\title{
Strategic Plan for the Utilization of Remote Sensing Technologies in the Environmental Restoration Program
}

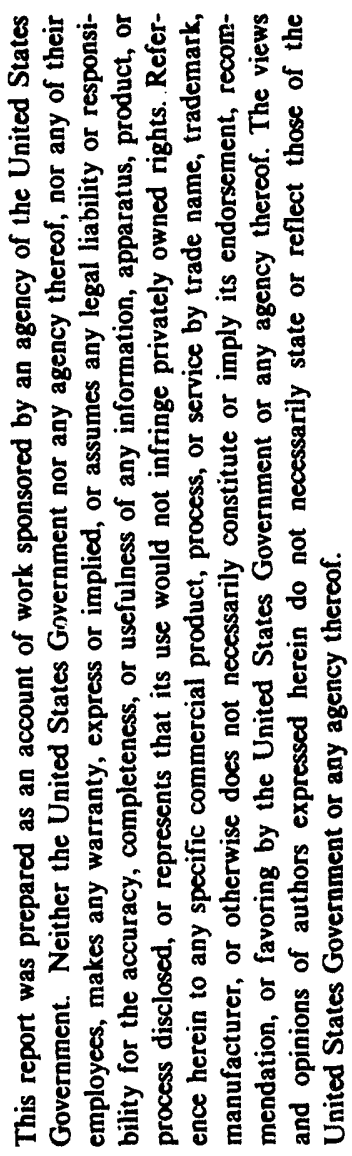

\author{
A. D. King W. E. Doll \\ R. C. Durfee R. J. Luxmoore \\ S. R. Conder J. E. Nyquist \\ Environmental Restoration Program \\ P.O. Box 2003 \\ Oak Ridge, Tennessee $37831-7298$
}

Date Issued-March 1994

Prepared by

Health Sciences Research Division

Oak Ridge National Laboratory

Prepared for

U.S. Department of Energy

Office of Environmental Restoration and Waste Management

under budgeting and reporting code EX 20

MARTIN MARIETTA ENERGY SYSTEMS, INC.

managing the

Oak Ridge K-25 Site

Oak Ridge Y-12 Plant

Oak Ridge National Laboratory under contract DE-AC05-84OR21400
Paducah Gaseous Diffusion Plant

Portsmouth Gaseous Diffusion Plant under contract DE-AC05-76OR00001

U.S. DEPARTMENT OF ENERGY 


\section{CONTENTS}

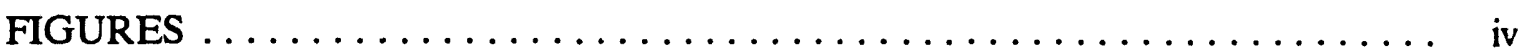

ACRONYMS $\ldots \ldots \ldots \ldots \ldots \ldots \ldots \ldots \ldots \ldots \ldots \ldots \ldots \ldots$

ACKNOWLEDGEMENTS $\ldots \ldots \ldots \ldots \ldots \ldots \ldots \ldots \ldots \ldots \ldots \ldots \ldots$ vi

EXECUTTVE SUMMARY $\ldots \ldots \ldots \ldots \ldots \ldots \ldots \ldots \ldots \ldots \ldots \ldots \ldots \ldots$

1. INTRODUCTION $\ldots \ldots \ldots \ldots \ldots \ldots \ldots \ldots \ldots \ldots \ldots \ldots \ldots \ldots \ldots \ldots$

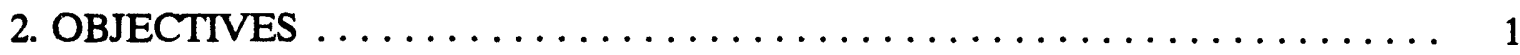

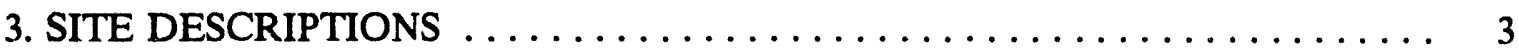

3.1 OAK RIDGE RESERVATION $\ldots \ldots \ldots \ldots \ldots \ldots \ldots \ldots \ldots \ldots \ldots \ldots \ldots \ldots$

3.2 PADUCAH GASEOUS DIFFUSION PLANT $\ldots \ldots \ldots \ldots \ldots \ldots \ldots \ldots$

3.3 PORTSMOUTH GASEOUS DIFFUSION PLANT $\ldots \ldots \ldots \ldots \ldots \ldots \ldots$

4. REMOTE SENSING METHODS $\ldots \ldots \ldots \ldots \ldots \ldots \ldots \ldots \ldots \ldots \ldots \ldots$

4.1 HIGH RESOLUTION GAMMA RADIATION SURVEY .......... 5

4.2 MULTISPECTRAL SCANNER IMAGERY $\ldots \ldots \ldots \ldots \ldots \ldots \ldots \ldots$

4.3 FALSE COLOR INFRARED PHOTOGRAPHY $\ldots \ldots \ldots \ldots \ldots \ldots \ldots$

4.4 NATURAL COLOR PHOTOGRAPHY $\ldots \ldots \ldots \ldots \ldots \ldots \ldots \ldots$

4.5 MAGNETIC DETECTION METHODS $\ldots \ldots \ldots \ldots \ldots \ldots \ldots \ldots \ldots \ldots$

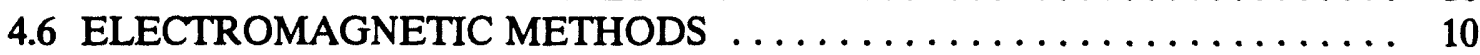

5. PRIOR AND CURRENT SURVEY ACTIVITIES $\ldots \ldots \ldots \ldots \ldots \ldots \ldots \ldots \ldots 11$

5.1 OAK RIDGE RESERVATION-HISTORIC SURVEYS $\ldots \ldots \ldots \ldots \ldots \ldots 11$

5.1.1 Phase I Photographic, Imagery, and Radiological Surveys . . . . . . . 11

5.1 .2 Phase II Geophysical Surveys . . . . . . . . . . . . . . . . 19

5.2 PADUCAH GASEOUS DIFFUSION PLANT $\ldots \ldots \ldots \ldots \ldots \ldots \ldots \ldots . \ldots \ldots$

5.3 PORTSMOUTH GASEOUS DIFFUSION PLANT $\ldots \ldots \ldots \ldots \ldots \ldots \ldots$

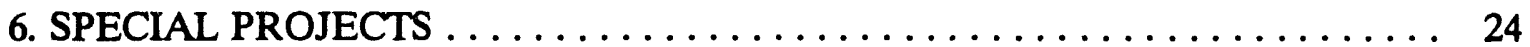

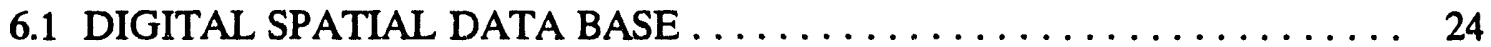

6.2 LASER-INDUCED FLUORESCENCE $\ldots \ldots \ldots \ldots \ldots \ldots \ldots \ldots \ldots \ldots$

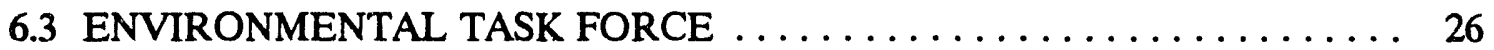

7. DATA MANAGEMENT $\ldots \ldots \ldots \ldots \ldots \ldots \ldots \ldots \ldots \ldots \ldots \ldots \ldots \ldots$

7.1 OAK RIDGE ENVIRONMENTAL INFORMATION SYSTEM . . . . . . 27

7.2 DATA PROCESSING AND IMAGE ANALYSIS $\ldots \ldots \ldots \ldots \ldots \ldots \ldots \ldots . \ldots \ldots$

7.3 DATA AND HARD COPY PRODUCTS $\ldots \ldots \ldots \ldots \ldots \ldots \ldots \ldots \ldots$

8. THE SAVANNAH RIVER SITE EXPERIENCE $\ldots \ldots \ldots \ldots \ldots \ldots \ldots \ldots \ldots . . \ldots 1$ 
9. NEW DEVELOPMENTS IN REMOTE SENSING

TECHNIQUES

10. PLAN FOR SURVEILLANCE, MONITORING, DATA

MANAGEMENT AND ANALYSIS $\ldots \ldots \ldots \ldots \ldots \ldots \ldots \ldots \ldots . \quad 32$

10.1 MULTISPECTRAL IMAGERY AND AERIAL PHOTOGRAPHY $\ldots \ldots \quad 32$

10.2 RADIOLOGICAL SURVEYS $\ldots \ldots \ldots \ldots \ldots \ldots \ldots \ldots \ldots \ldots \ldots \ldots \ldots \ldots \ldots \ldots$

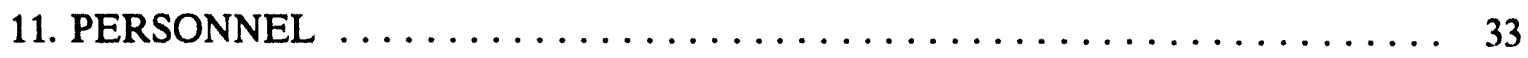

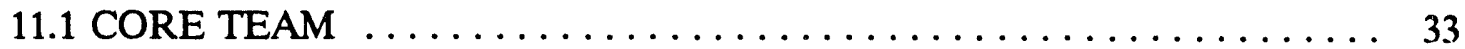

11.2 STEERING COMMITTEE $\ldots \ldots \ldots \ldots \ldots \ldots \ldots \ldots \ldots \ldots \ldots \ldots \ldots \ldots \ldots$

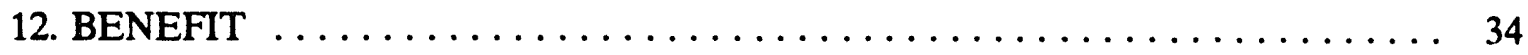




\section{FIGURES}

1 DOE-Oak Ridge , erations facilities operated

by Energy Systems (Oak Ridge, Paducah, and Portsmouth) $\ldots \ldots \ldots \ldots \ldots 2$

2 High altitude aerial photograph of the Oak Ridge Reservation,

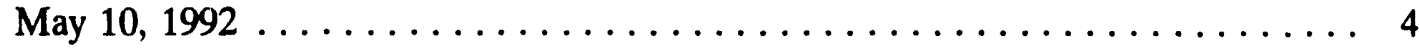

3 Aerial photograph of the Paducah Gaseous Diffusion Plant $\ldots \ldots \ldots \ldots \ldots$

4 Aerial photograph of the Portsmouth Gaseous Diffusion Plant . . . . . . . . . 7

$5 \quad$ False color infrared aerial photograph (3000-ft altitude)

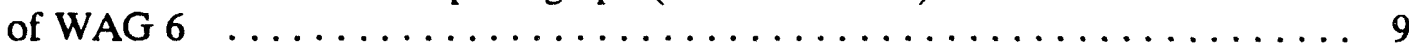

6 Oak Ridge Reservation gamma survey gross count contours

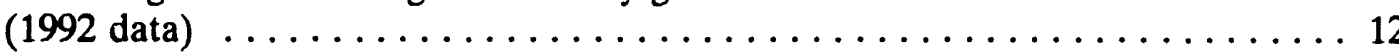

7 Manmade gamma contours (1992 data) overlaid on a 3000-ft

color infrared orthophoto mosaic of ORNL $\ldots \ldots \ldots \ldots \ldots \ldots \ldots \ldots$

8 Preliminary landcover map of ORNL with 11 landcover classes

derived from six principal components from 12 multispectral

scanner bands using statistical imaging techniques $\ldots \ldots \ldots \ldots \ldots \ldots$

9 Normalized-difference vegetation index image of WAG 6 computed from 1992 Airborne Daedalus DS-1260 multispectral

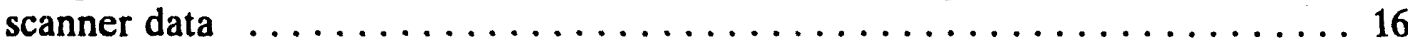

10 Thermal infrared analysis and isoline map of WAG 6 derived from 1992 thermal data . . . . . . . . . . . . . . . . . . . . . . . 17

11 Vertical magnetic gradient map of the WAG 6 waste site $\ldots \ldots \ldots \ldots \ldots 20$

12 Apparent electrical conductivity map of the Oak Ridge Reservation derived from phase II electromagnet surveys $\ldots \ldots \ldots \ldots \ldots \ldots \ldots \ldots$

13 A sample Geographic Information System screen showing monitoring wells in WAG 6 mapped on top of rectified aerial photography and map data along with an interactive table

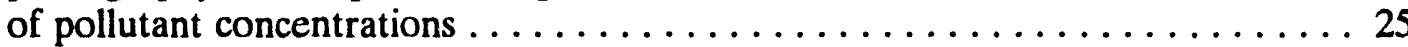

14 Flowchart showing how geographic and remotely sensed data are input, rectified, analyzed, and stored 


\section{ACRONYMS}

\begin{tabular}{ll} 
AGL & above-ground level \\
DOE & U.S. Department of Energy \\
EM & electromagnetic \\
Energy Systems & Martin Marietta Energy Systems, Inc. \\
ER & Environmental Restoration \\
ERWM & Environmental Restoration and Waste Management \\
ETF & Environmental Task Force \\
FFA & Federal Facility Agreement \\
FY & fiscal year \\
GIS & Geographic Information System \\
GPS & Global Positioning System \\
GWOU & Groundwater Operable Unit \\
HEM & Helicopter Electromagnetic \\
IAG & Interagency Agreement \\
INEL & Idaho National Engineering Laboratory \\
IR & infrared \\
LIF & laser-induced fluorescence \\
MSS & Multispectral Scanner \\
NTM & National Technical Means \\
OREIS & Oak Ridge Environmental Information System \\
ORNL & Oak Ridge National Laboratory \\
ORO & Oak Ridge Operations \\
ORR & Oak Ridge Reservation \\
PCB & polychlorinated biphenyl \\
PGDP & Paducah Gaseous Diffusion Plant \\
PORTS & Portsmouth Gaseous Diffusion Plant \\
QA VC & quality assurance/quality control \\
SERDP & Strategic Environmental Research and Development Project \\
SRS & Savannah River Site \\
TCE & trichloroethylene \\
TOA & Tennessee Oversight Agreement \\
TVA & Tennessee Valley Authority \\
WAG & waste area grouping \\
& \\
& \\
\hline &
\end{tabular}




\section{ACKNOWLEDGEMENTS}

A. D. King is a member of the Health Sciences Research Division, Oak Ridge National Laboratory; W. E. Doll, R. J. Luxmoore, and J. E. Nyquist are members of the Environmental Sciences Division, Oak Ridge National Laboratory; R. C. Durfee is a member of the Computing Applications Division, Oak Ridge National Laboratory; S. R. Conder is a subcontractor with the University of Tennessee, Knoxville, Tennessee. 


\section{EXECUTIVE SUMMARY}

The objectives of the Environmental Restoration (ER) Remote Sensing and Special Surveys Program are to apply state-of-the-art remote sensing and geophysical technologies and to manage routine and remotely-sensed examinations of the Oak Ridge Reservation (ORR), the Paducah Gaseous Diffusion Plant (PGDP), the Portsmouth Gaseous Diffusion Plant (PORTS), and their adjacent off-site areas. Repeated multispectral scanner (MSS) imagery, gamma, and photographic surveys will allow monitoring of the degradation that might occur in waste containment vessels and monitoring (at a later stage in the remediation life cycle) of improvements from restoration efforts and cleanup. These technologies, in combination with geophysical surveys, will provide an effective means for identifying unknown waste sites and contaminant transport pathways. All of the data will be maintained in a data base that will be accessible to site managers in the ER Program. The complete analysis of collected data will provide site-specific data to the ER Program for characterizing and monitoring ER Program hazardous waste sites. 


\section{INTRODUCTION}

The Environmental Restoration (ER) Remote Sensing and Special Surveys Program has been established to provide environmental site characterization data, change data, and trend data to Environmental Restoration and Waste Management (ERWM) programs at all of the five U.S. Department of Energy (DOE) facilities operated and managed by Martin Marietta Energy Systems, Inc. (Energy Systems). The Remote Sensing and Special Surveys Program can provide a great resource to these facilities through various survey activities. The data acquired from the surveys can be used to obtain screening level information for locating potential contamination sources; aid in site characterization efforts; establish baselines for comparison with future conditions; provide a data base of information for detailed analysis, comparisons, and integration with field measurements and map data; assist in remedial investigation planning; and aid in long-term monitoring of environmental improvements from restoration activities.

\section{OBJECTIVES}

The objectives of the Remote Sensing and Special Surveys Program are to apply state-ofthe-art remote sensing and geophysical technologies and to manage routine and remotely-sensed examinations of the Oak Ridge Reservation (ORR), the Paducah Gaseous Diffusion Plant (PGDP), the Portsmouth Gaseous Diffusion Plant (PORTS), and adjacent off-site areas. Remote sensing technologies are effective methods for acquiring important data needed for the missions of ERWM programs on the ORR, PGDP, and PORTS facilities and their adjacent off-site areas. The locations of the three facilities included in this strategic plan are within about $500 \mathrm{~km}$ ( 310 miles) of each other (Fig. 1). These technologies will be of value throughout the DOE remediation life cycle by previding efficient site characterization, detection of temporal changes associated with contaminant transport or remediation efforts, and geographic data base improvements (e.g., facility layout, land cover, topography).

Remote sensing surveys can provide data necessary for documenting changes in land use and waste site activity, as well as associated impacts of these changes on vegetation and water resources. Low altitude radiological surveys, multispectral scanning, and photographic surveys conducted at several altitudes using cameras carrying infrared and natural color film can provide a broad range of landscape characterization data. Repeated multispectral scanner (MSS) imagery, gamma, and photographic surveys will allow monitoring of the degradation that might occur in waste containment vessels and monitoring of improvements from restoration efforts and cleanup at a later stage in the remediation life cycle. Additionally, airborne geophysical methods extend the surveillance to several meters into the soil $(100 \mathrm{~m}$ or more), allowing identification of anomalies recorded as magnetic or resistivity changes. Combining geophysical data and remote sensing data will create an effective means for identifying unknown waste sites and contaminant transport pathways. 


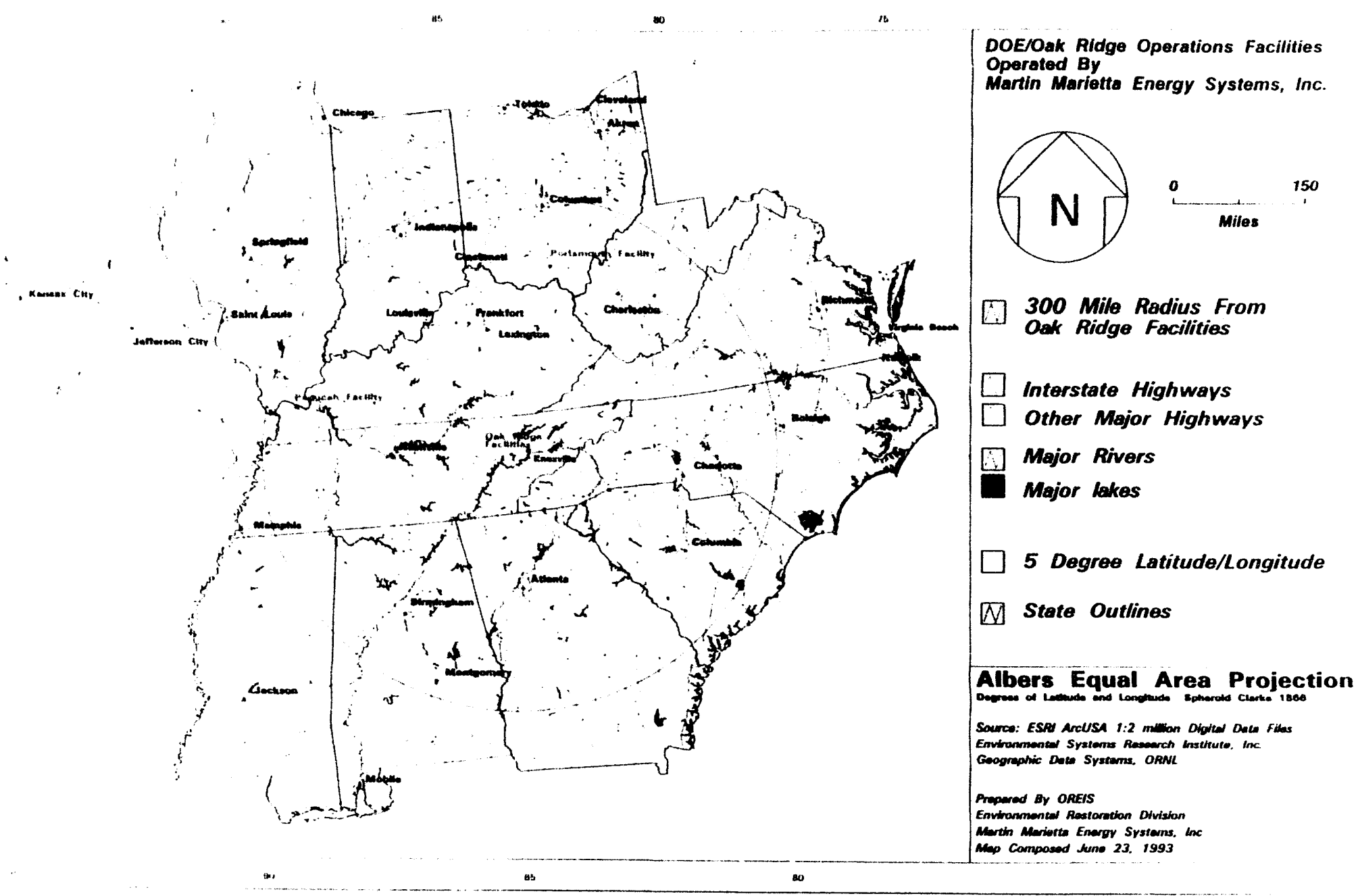

Fig. 1. DOE-Oak Ridge Operations facilities operated by Energy Systems (Oak Ridge, Paducah, and Portsmouth). 
Continuing developments in remote sensor capabilities and instrumentation will enhance the sensitivity of remote sensing surveys to detect features resulting from former land use practices. Vegetation stress and changes in the groundwater behavior of water seeps may develop in the future as shallow land burial sites degrade or as the physical plant structures corrode (e.g., underground pipes). Possible contaminant transport pathways may be identified by studying the spatial relationship of seeps, springs, and saturated areas to the surrounding topography and water bodies and by analyzing the low electrical resistivity anomalies in the airborne electromagnetic (EM) data. As cleanup work progresses, remote sensing techniques can aid in monitoring various long-term changes and improvements to the DOE lands of the ORR, PGDP, PORTS, and surrounding offsite areas.

All of the data will be maintained in a data base that will be accessible to site managers in the ER Program. The complete analysis of collected data will provide site-specific data to the ER Program for characterizing and monitoring ER Program hazardous waste sites.

\section{SITE DESCRIPTIONS}

\subsection{OAK RIDGE RESERVATION}

The ORR consists of 14,266 ha $(35,252$ acres) of federally-owned land. The DOE K-25 Site, Y-12 Plant, and Oak Ridge National Laboratory (ORNL) account for approximately 1200 ha (3000 acres) of this land, while the remaining area is relatively undeveloped (Fig. 2). During the last 50 years of operations, DOE has used a variety of land disposal techniques on the ORR, causing soil, sediment, surface water, and groundwater contamination. This contamination has resulted in unacceptable human health and ecological risks on the ORR and some off-site contamination of local stream and river systems draining from the ORR. Examples of techniques employed for hazardous waste disposal include trench percolation, shallow land burial, liquid waste injection, deep injection by hydrofracture, land application for biodegradation of organic wastes, and surface dumping.

The DOE-ER Program has documented much of the extent, methods, and risks of contamination on the ORR. However, gaps have been identified in the records of waste operations, and a fire destroyed some records. More information is needed before DOE can achieve confidence that all potentially hazardous sites have been iocated. Continuing corrosion of waste site containers may result in increased contaminant migration through the landscape with time. Such releases could have detrimental impacts on vegetation and water resources on the ORR. A sustained effort is needed to monitor the ORR in an efficient and effective way so that any contaminant problems can be quickly identified and remedial action taken.

\subsection{PADUCAH GASEOUS DIFFUSION PLANT}

The PGDP site is a uranium enrichment facility consisting of a diffusion cascade and extensive support activities. The cascade is housed in five buildings covering approximately 


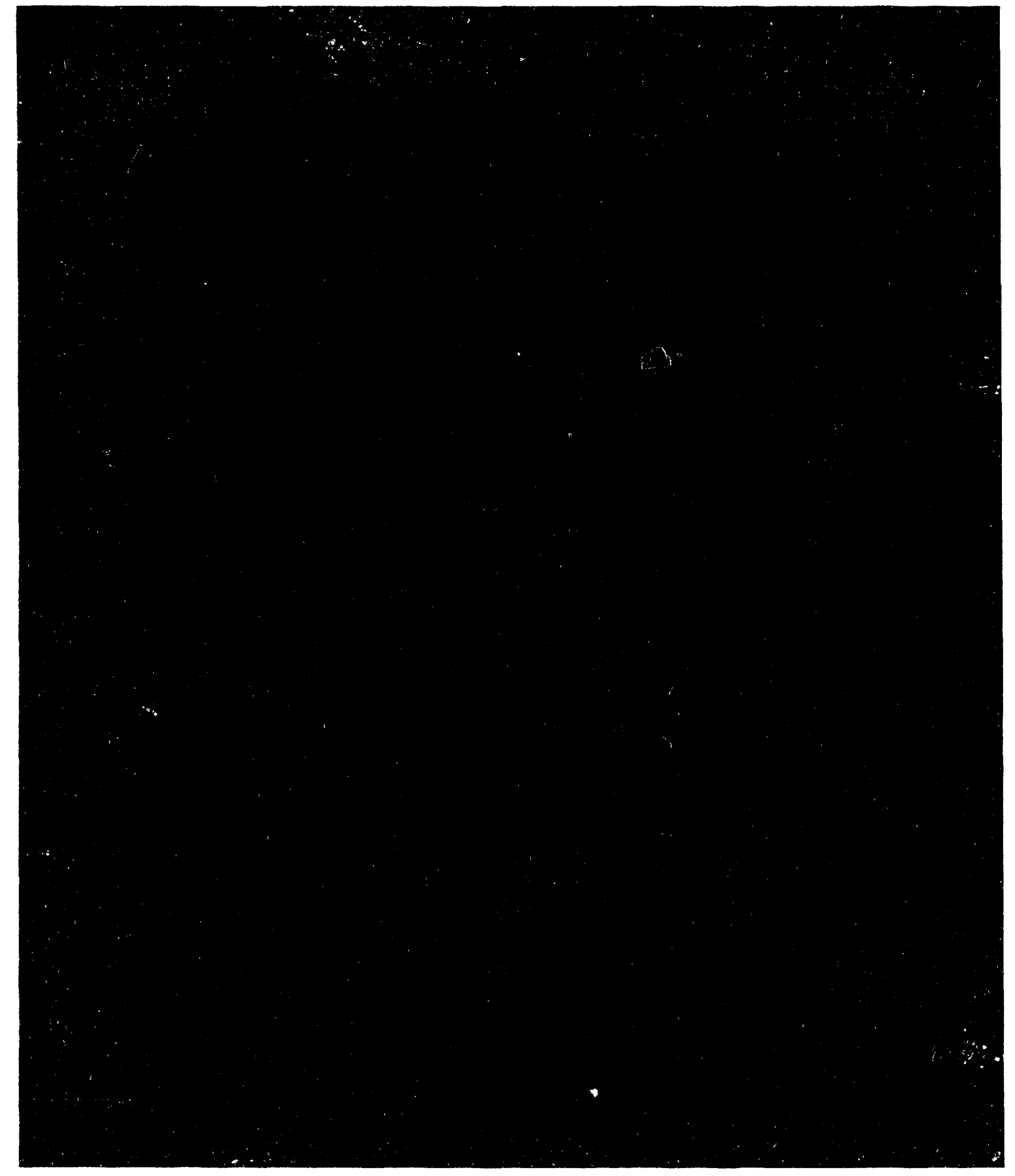

Fig. 2. High altitude (40,000 ft) aerial photograph of the Oak Ridge Reservation, May 10, 1992. 
30 ha (75 acres), and these buildings have been in continuous operation since 1952 . The operation currently supplies the feedstock for PORTS. As ciepicted in the aerial photograph presented in Fig. 3, the PGDP facility is located in McCracken County, Kentucky, approximately $5.6 \mathrm{~km}$ south of the Ohio River and $24 \mathrm{~km}$ west of the city of Paducah. The Shawnee Steam Plant of the Tennessee Valley Authority (TVA) borders the DOE property to the northeast. The PGDP is on a 1385 -ha site owned by DOE, and the plant facility is within a fenced security area of 303 ha. A few support operations (landfill, water treatment plant) are outside the plant security area. The DOE maintains a buffer zone of 237 ha surrounding the security area. The remaining 845 ha of DOE land is deeded or leased to the Commonwealth of Kentucky as part of the West Kentucky Wildlife Management Area (Fig. 3). Hazardous, nonhazardous, and radioactive wastes have been generated and disposed of as a result of plant operations. The contaminants of concern from the operations are technetium-99 (from processing reactor tails), polychlorinated biphenyls (PCBs), and trichloroethylene (TCE). Environmental releases of TCE have occurred through spills; leaks; vapor emissions; and discharges to soils, surface water, and groundwater.

\subsection{PORTSMOUTH GASEOUS DIFFUSION PLANT}

As shown in Fig. 4, the PORTS facility is located in sparsely populated, rural Pike County, Ohio, on a 1632-ha (4033-acre) site about $4.2 \mathrm{~km}(2.6 \mathrm{mi})$ east of the Scioto River Valley. The average land surface is $204 \mathrm{~m}(670 \mathrm{ft})$ above mean sea level and is approximately $37 \mathrm{~m}(120 \mathrm{ft})$ above the Scioto River floodplain. The PORTS facility, which has been operational since 1954, enriches uranium for naval and commercial nuclear reactors. Support operations include the feed and withdrawal of material from the primary diffusion separation process, treatment of water for both potable and cooling purposes, steam generation, recovery of uranium from various waste materials, and treatment of industrial wastes. The construction and operation of the facility require use of commercially available chemicals and result in generation of low-level radioactive, inorganic, and organic wastes.

\section{REMOTE SENSING METHODS}

A brief description of several remote sensing methods outlines some basic features and the utility of the surveys for surveillance of DOE lands.

\subsection{HIGH RESOLUTION GAMMA RADIATION SURVEY}

This survey method requires a helicopter outfitted with one or two detector pods, a computer-based data acquisition system, and an accurate triangulation positioning system. Each detector pod houses (five) sodium iodide gamma ray detectors which measure the ground-level gamma energy spectrum in the 38 to $3026 \mathrm{KeV}$. Through interpretation of the spectral energies, data can be presented as gross gamma energy (background plus manmade), total manmade gamma energy, or as direct or indirect (i.e., daughter) gamma energy from specific radionuclides (e.g. cesium-137, cobalt-60, uranium-238). This type of survey will provide a good characterization of DOE contamination areas since many of the radioactive 


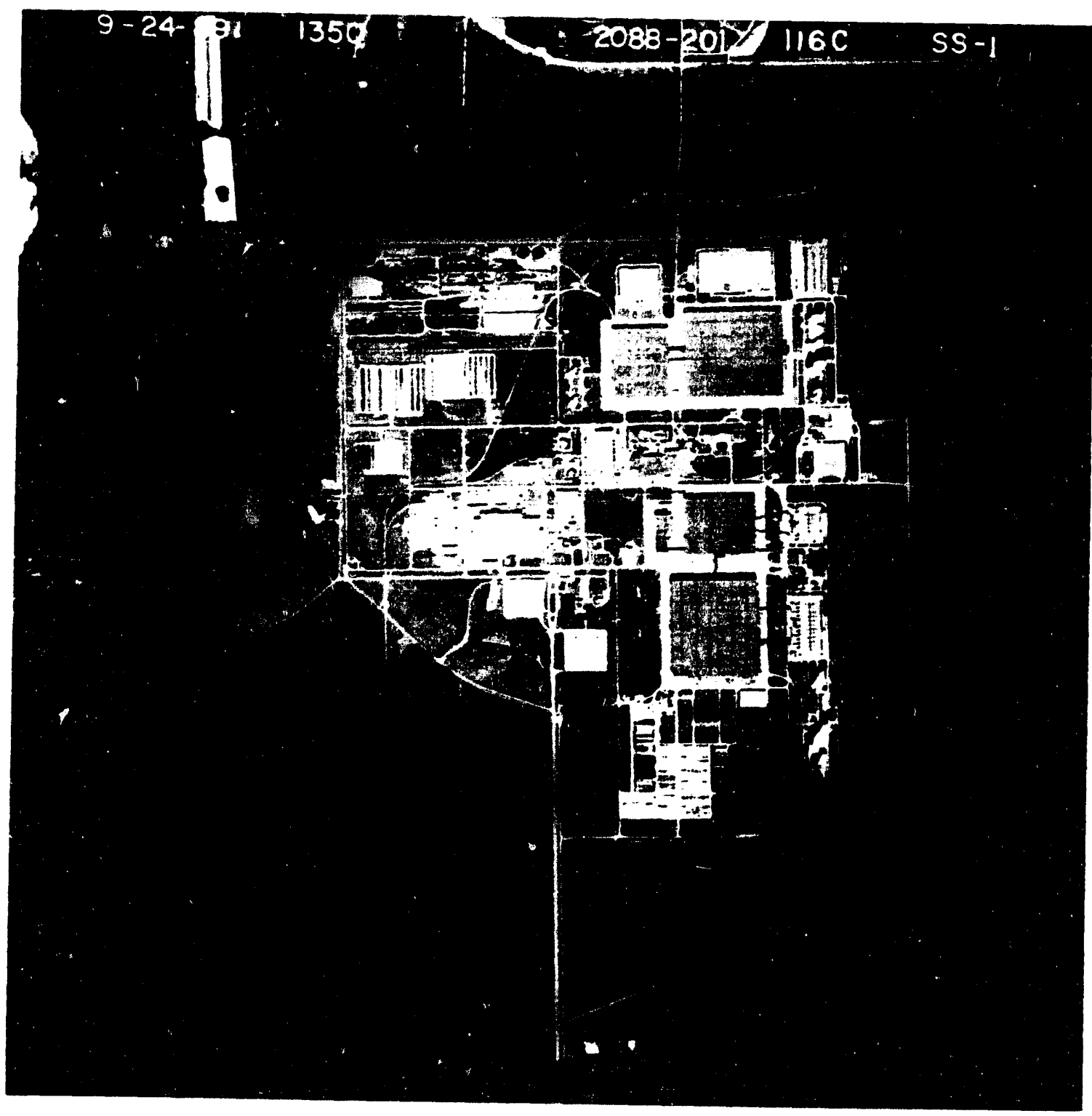

Fig. 3. Aerial photograph of the Paducah Gaseous Diffusion Plant, September 24, 1989. 


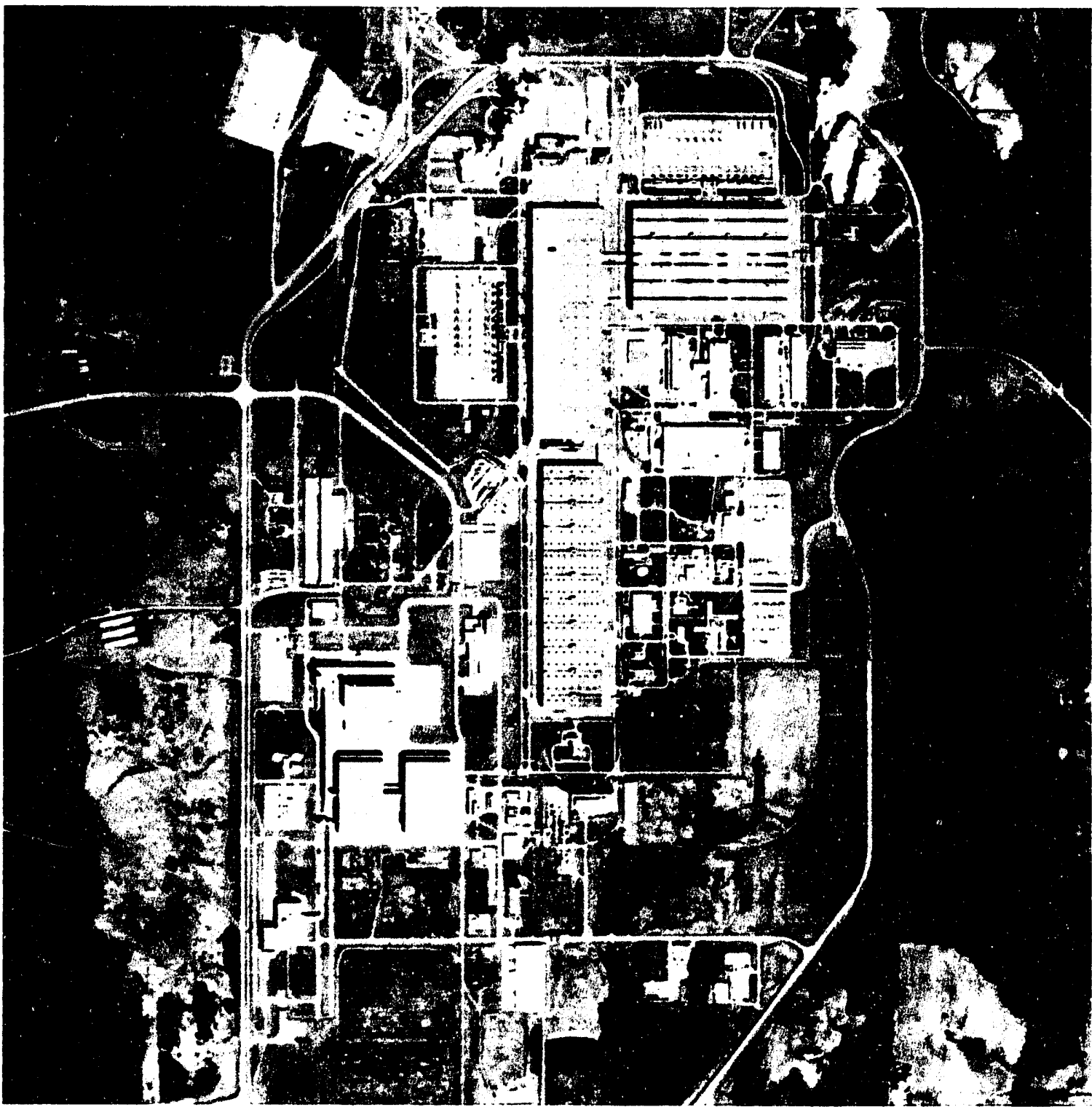

Fig. 4. Aerial photograph of the Portsmouth Gaseous Diffusion Plant. 
materials processed or handled on the ORR, PGDP, and PORTS are direct gamma radiation emitters or have gamma emitting daughter radionuclides. Surveys can be conducted at $150 \mathrm{ft}$ $(46 \mathrm{~m})$ altitude with areas near power lines and obstructions flown at higher altitudes. Greater gamma sensitivity can be obtained with soil at low water content, favoring surveys during the late summer and autumn period (August-October).

\subsection{MULTISPECTRAL SCANNER IMAGERY}

The MSS imagery technique uses a commercial (e.g., Daedalus) or custom-built scanning spectrometer flown in a small jet aircraft (e.g., Cessna Citation). The MSS spectrometer digitally records the reflectance and emissions of EM radiation from the earth's surface and partitions the records into 12 distinct wavebands ranging from ultraviolet to thermal infrared, including two thermal channels of the same wavelength but different intensities. Aerial measurements can be obtained during the daytime and at predawn to enhance detection of diurnal temperature changes through comparison of the two thermal patterns.

One of the important uses of MSS imagery in environmental studies is detection of unnatural vegetative stress induced by soil and/or groundwater contamination of the root zone. Vegetation under stress exhibits different light absorption and reflectance properties (hence different MSS images) than the same species in non-stressed conditions. Another use of MSS is the detection of temperature differences, which may be indicative of seeps or heated effluents, in surface waters.

Representative altitudes above ground level (AGL) flown for MSS imagery are $3000 \mathrm{ft}$ $(914 \mathrm{~m})$ and $6000 \mathrm{ft}(1829 \mathrm{~m})$ during the day and at $4000 \mathrm{ft}(1219 \mathrm{~m})$ during the predawn period. The daytime MSS may also be analyzed to produce land cover/land use data bases. After geographic rectification, comparisons can be made with similar data from previous time periods to detect temporal changes and identify surface anomalies.

\subsection{FALSE COLOR INFRARED PHOTOGRAPHY}

False color infrared (IR) photography blocks out visible light reflectance in the green waveband region of the visible spectrum and intensifies the near infrared bands. False color IR provides a valuable means for locating vegetation anomalies and water-saturated areas. Variation in color IR reflectances from settling ponds and lakes is an aid to determining water conditions, sedimentation, and algal growth. False color IR photos are usually obtained during the daytime flights used for MSS and are flown at $3000 \mathrm{ft}(914 \mathrm{~m})$ and $6000 \mathrm{ft}(1829 \mathrm{~m})$ AGL. An example of 3000 -ft color IR photography is illustrated in Fig. 5.

\subsection{NATURAL COLOR PHOTOGRAPHY}

Aerial photos are beneficial in environmental investigations because they allow an investigator to obtain a visual perspective of the site geographic and cultural features that may complement other environmental measurements. For example, aerial gamma radiation data can be overlain on a natural color photo to provide increased accuracy in data interpretation as well as identification of surface features that may relate to the radiation. High resolution 


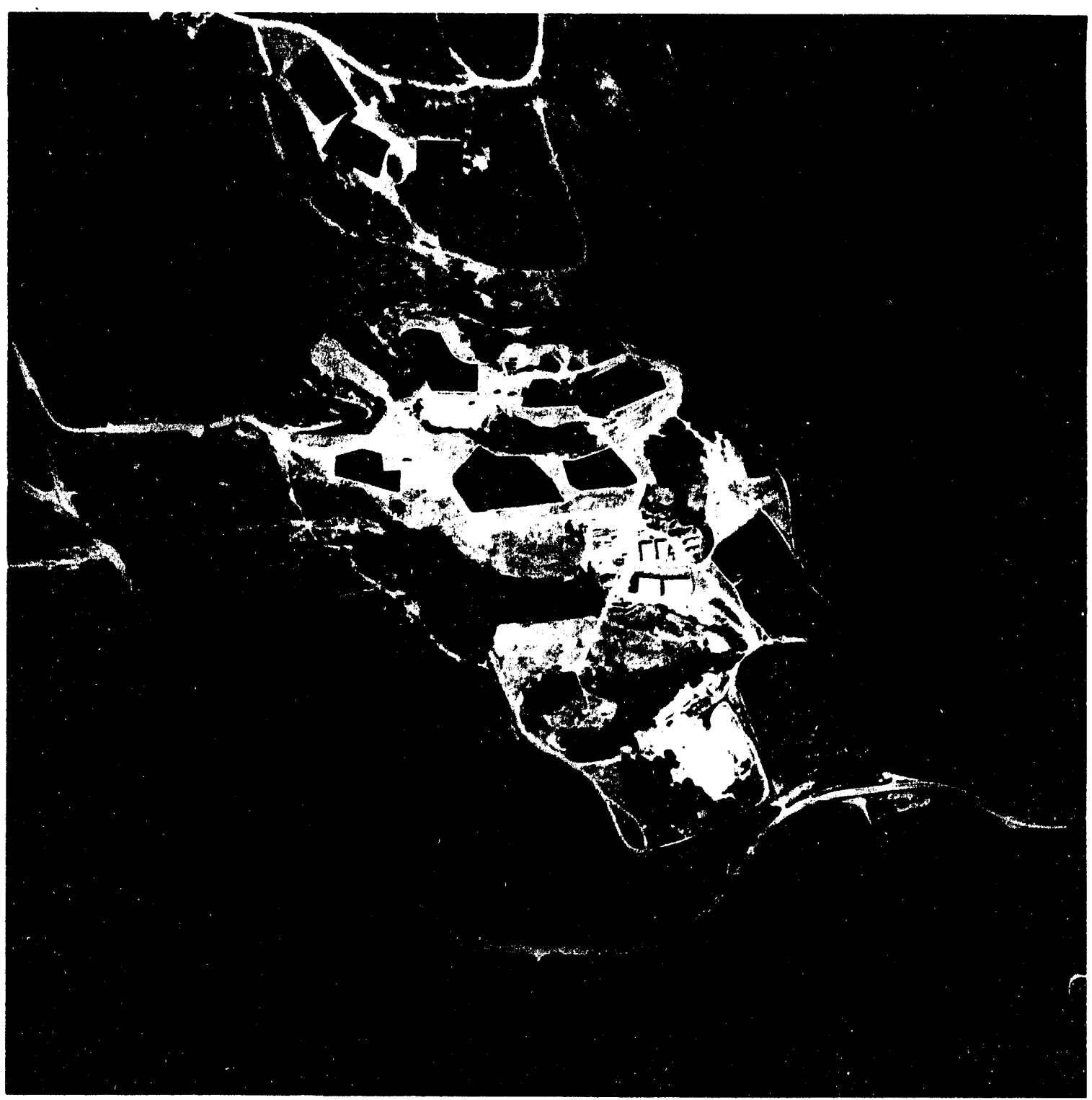

Fig. 5. False color infrared aerial photograph (3000-ft altitude) of WAG 6. 
natural color photos are usually taken from flight altitudes of $6000 \mathrm{ft}(1829 \mathrm{~m})$ and $9500 \mathrm{ft}$ (2896 m) AGL, and these can be georectified and scaled to provide a base for overlay of map data such as contours derived from other aerial surveys (e.g., gamma radiation, surface temperature). At $43,000 \mathrm{ft}(13,106 \mathrm{~m}) \mathrm{AGL}$, the entire ORR can be shown on one photograph. Aerial photos provide current information on surface features and characteristics needed for updating earlier maps and data bases.

\subsection{MAGNETIC DETECTION METHODS}

Surface and airborne measurements of perturbations in the direction and/or strength of the earth's magnetic field are used to locate magnetized objects or structures in the subsurface. These methods have typically been used to locate or characterize geologic features but are also effective at locating manmade objects composed of materials that can become magnetized. Although both total field and directional (e.g., vertical component) magnetometers can be deployed in fixed wing aircraft, such deployment is unable to achieve a low enough altitude and slow enough air speed to give sufficient resolution required for the purposes of this program. For helicopter surveys, the greatest sensitivity and shortest repeat interval are achieved with instruments employing "optically pumped" sensors, such as cesium or rubidium magnetometers. These instruments are often deployed in pairs and arranged with one lying directly above the other at a fixed spacing to measure vertical magnetic gradients. Such an instrument is referred to as a magnetic gradiometer.

Surface (total field) magnetic measurements are typically made with proton precession magnetometers. Altitude and flight path spacing, along with natural and instrument noise levels, determine the minimum size of the target that can be detected using airborne methods. Depths of several kilometers may be detected with aeromagnetic instruments. The capability of detecting a single 55-gal drum from the air has been reported, but groups of drums are more likely a minimum target size. Surface magnetic measurements can be used in follow-up surveys to detect much smaller objects.

\subsection{ELECTROMAGNETIC METHODS}

Detection schemes based on the amplitude and phase of a time-varying EM field induced in the earth are useful for determining changes in the resistivity of the medium. Many of these methods have been adapted to aerial surveillance from the mineral survey industry. Modern airborne EM systems use multifrequency sensors with each of the three or five frequencies being generated and received by a pair (one transmitter and one receiver) of vertical coaxial or horizontal coplanar coils. The coil orientation (vertical coaxial or horizontal coplanar), frequency, and resistivities of the target and the host determine the shape and penetration depth of anomalies to which the coil pair is sensitive. Penetration depths of a few feet for the high frequencies $(>36 \mathrm{kHz}$ ) and a few hundred feet for the lower frequencies $(<800 \mathrm{~Hz})$ are typical.

Airborne EM data may be collected during the same flight as aeromagnetic data by applying proper design criteria. Because they are sensitive to change in resistivity rather than magnetic properties, EM instruments can detect objects to which magnetic surveying is insensitive, such as cement or stainless steel structures. For typical metallic objects, airborne EM methods are less sensitive than aeromagnetic measurements. Electromagnetic instruments 
are generally better suited for the detection of geologic and hydrogeologic structures. Surface EM measurements can improve the resolution of shallow targets. These measurements provide an effective way to check suspicious areas that are identified during an airborne survey.

\section{PRIOR AND CURRENT SURVEY ACTIVTTIES}

\subsection{OAK RIDGE RESERVATION-HISTORIC SURVEYS}

Aerial photographic surveys (both plane view and oblique) have been carried out for the ORR over the last several decades, including both natural color and black-and-white photography. Several gamma radiation surveys have been conducted for different parts of the ORR during the last 30 years. The first survey was conducted by the U.S. Geological Survey in 1959 to characterize the radiogeology of the ORR. This survey was conducted from a fixedwing aircraft at an altitude of $500 \mathrm{ft}(152 \mathrm{~m})$ and at $1.6 \mathrm{~km}$ (1 mile) spacing. A repeat survey from a fixed-wing aircraft was conducted in 1973, and anomalous areas were resurveyed at $250 \mathrm{ft}(76 \mathrm{~m})$ altitude with helicopter-mounted instrumentation. The 1973 surveys and all subsequent radiological surveys were conducted by EG\&G Energy Measurements. Surveys conducted in 1980 and 1989 were made at $300 \mathrm{ft}(91 \mathrm{~m})$ altitude, and a specific survey in 1986 of the White Oak Creek floodplain was made at $150 \mathrm{ft}(46 \mathrm{~m})$ altitude.

\subsubsection{Phase I Photographic, Imagery, and Radiological Surveys}

\subsubsection{Survey specifications}

Phase 1 of the 1992 aerial surveillance included a high-resolution gamma radiation survey of approximately $80 \%$ of the ORR (Fig. 6), and photography and MSS missions of the entire ORR and several adjacent off-site areas. The radiological survey was conducted at $150 \mathrm{ft}$ $(46 \mathrm{~m})$ AGL providing the greatest spatial resolution and data sensitivity to date for this area. Multispectral scanner imagery (daytime and predawn), false color IR photography, and natural color photography were also obtained in April 1992 at various altitudes ranging from $3000 \mathrm{ft}$ $(914 \mathrm{~m})$ to $43,000 \mathrm{ft}(13,106 \mathrm{~m}) \mathrm{AGL}$.

\subsubsection{Preliminary results}

A final report on the Phase I radiological surveys of the ORR has been prepared by a DOE subcontractor. Digital gamma radiation contour data were received, converted, and loaded into workstations for further mapping and comparison with other imagery. A series of site and reservation-wide maps have been made of all the gamma data received so far. For selected areas, the gamma contours have been superimposed on scanned aerial photos in both 2-D and in 3-D with the terrain surface underneath. An example of this superimposition, showing manmade gamma contours overlaid on a 3-D perspective view of WAG 6 and ORNL, uses mosaic color IR orthophotos as a backdrop and is shown in Fig. 7. These 


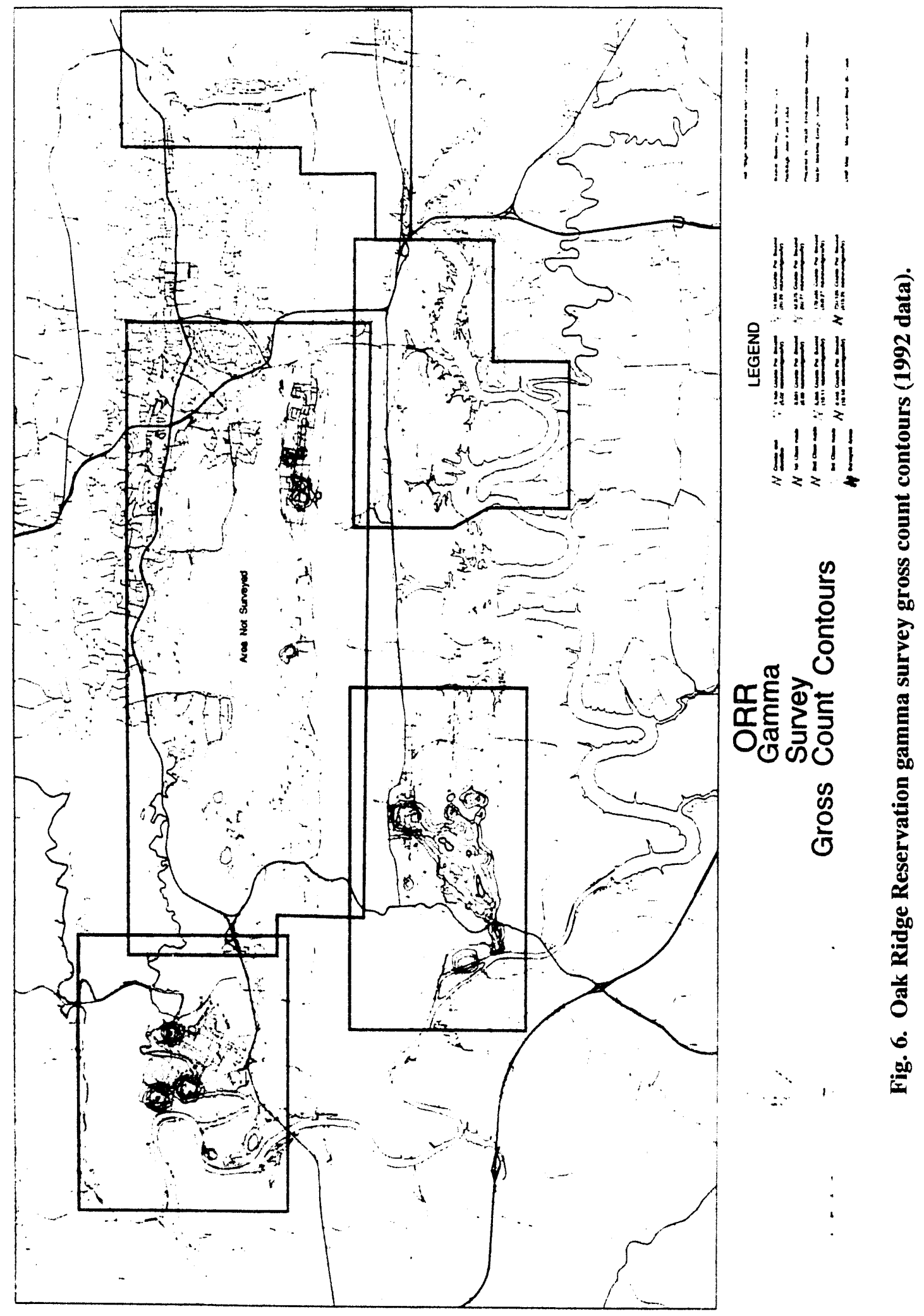




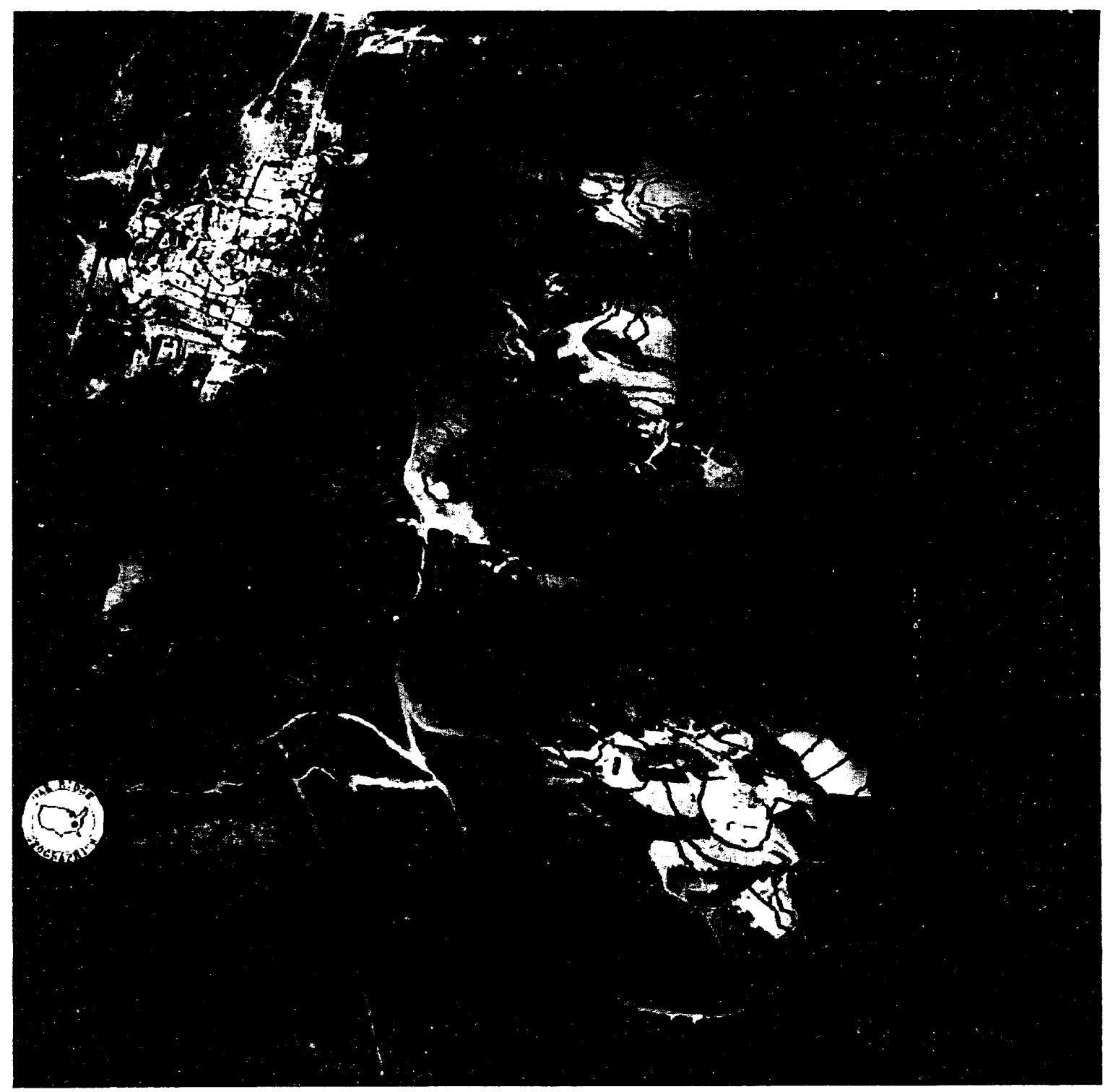

Fig. 7. Manmade gamma contours (1992 data) overlaid on a 3000-ft color infrared orthophoto mosaic of ORNL. 
results have been studied to gain further understanding of possible sources, distributions, and relationships to surrounding terrain features.

Portions of the natural color and color infrared photography have been scanned and processed using special imaging systems at ORNL. Rectified orthophotos and mosaics have been produced for each of the ORR facilities (ORNL, the Y-12 Plant, and the K-25 Site) and the whole reservation by using digital elevation models and known ground control points to geometrically correct the imagery. Some of the ground control has been acquired using accurate global positioning system (GPS) technology.

Radiometric techniques have been used to enhance and improve the color images to aid in map updates, terrain interpretation, and integration with other data. Multiple orthophotos have been mosaicked together to create composite images that can serve as a base on which to overlay all other types of geographic data for detailed interpretations. These images have been loaded into the Oak Ridge Environmental Information System (OREIS) for widespread use. A large variety of color hard copy products have been produced to aid in a number of studies. The rectified photos have also been used as a base for real-time GPS data acquisition and mapping from vehicles traveling on the ORR. Some updates of map information is being made from low-altitude aerial photos.

Statistical imaging algorithms have been used to analyze the MSS imagery and compute land use and land cover patterns for portions of the ORR (e.g., ORNL) (Fig. 8). A color atlas of MSS images is being completed for the whole reservation. Work has been done to test rectification techniques on the MSS data which are much more difficult to correct than stereo photographs. A series of MSS image transforms have been applied to selected areas to study land cover patterns and vegetative growth and to create vegetation indices and simulated color IR. One such transform is the Normalized-Difference Vegetative Index (NDVI), an example of which appears in Fig. 9.

The pre-dawn thermal imagery has been transformed and analyzed for seeps and springs at ORNL, the K-25 Site, and Parcel A. Portions of the thermal data were rectified and digitally integrated with scanned color photos, map data, and seep field surveys to correlate the results. Thermal contour maps were also produced. Suspect seeps and springs were delineated and displayed on the computer with color hard copy maps produced. Preliminary overlay of the seep field surveys and the thermal data show good correlations. The results of a thermal IR analysis of WAG 6 are presented in Fig. 10.

Sample videos from helicopter EM flyovers have been loaded onto laser video disks and integrated with digital workstations for selected browsing under locational control of a Geographic Information System (GIS). This has been done in both rideo and real-time digitized forms.

\subsubsection{Future Plans}

The use of remote sensing technology and data from Phase I and follow-on phases is just beginning. Five major stages are involved in applying the data and techniques to environmental restoration problems:

- acquisition of the remotely-sensed data; 


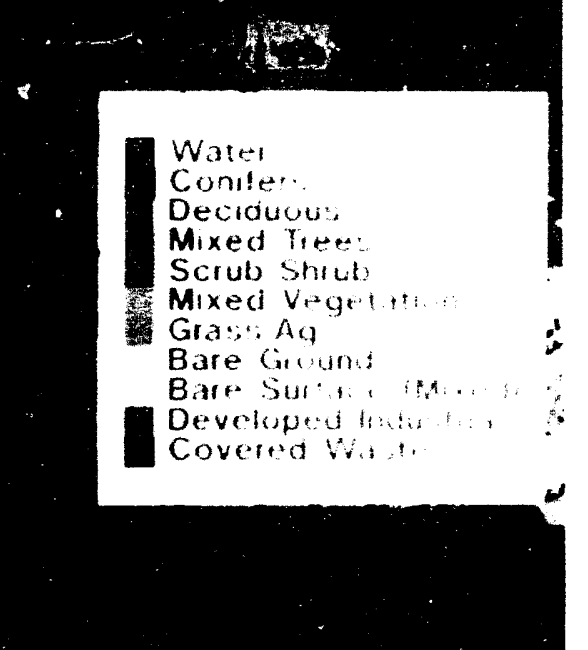

Fig. 8. Preliminary landcover map of ORNL with 11 landcover classes derived from six principal components computed from 12 multispectral scanner bands (1992 data) using statistical imaging techniques. 

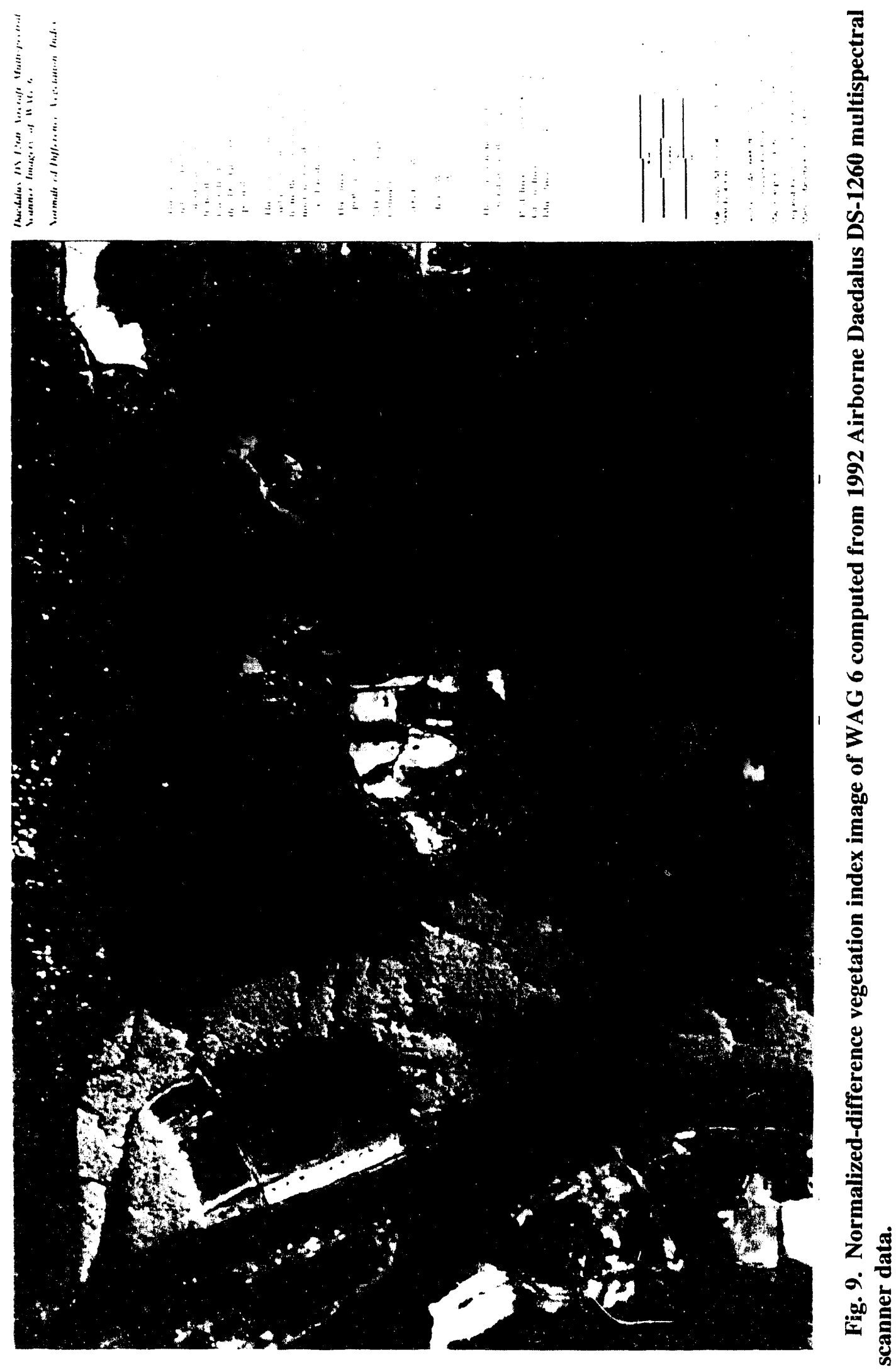


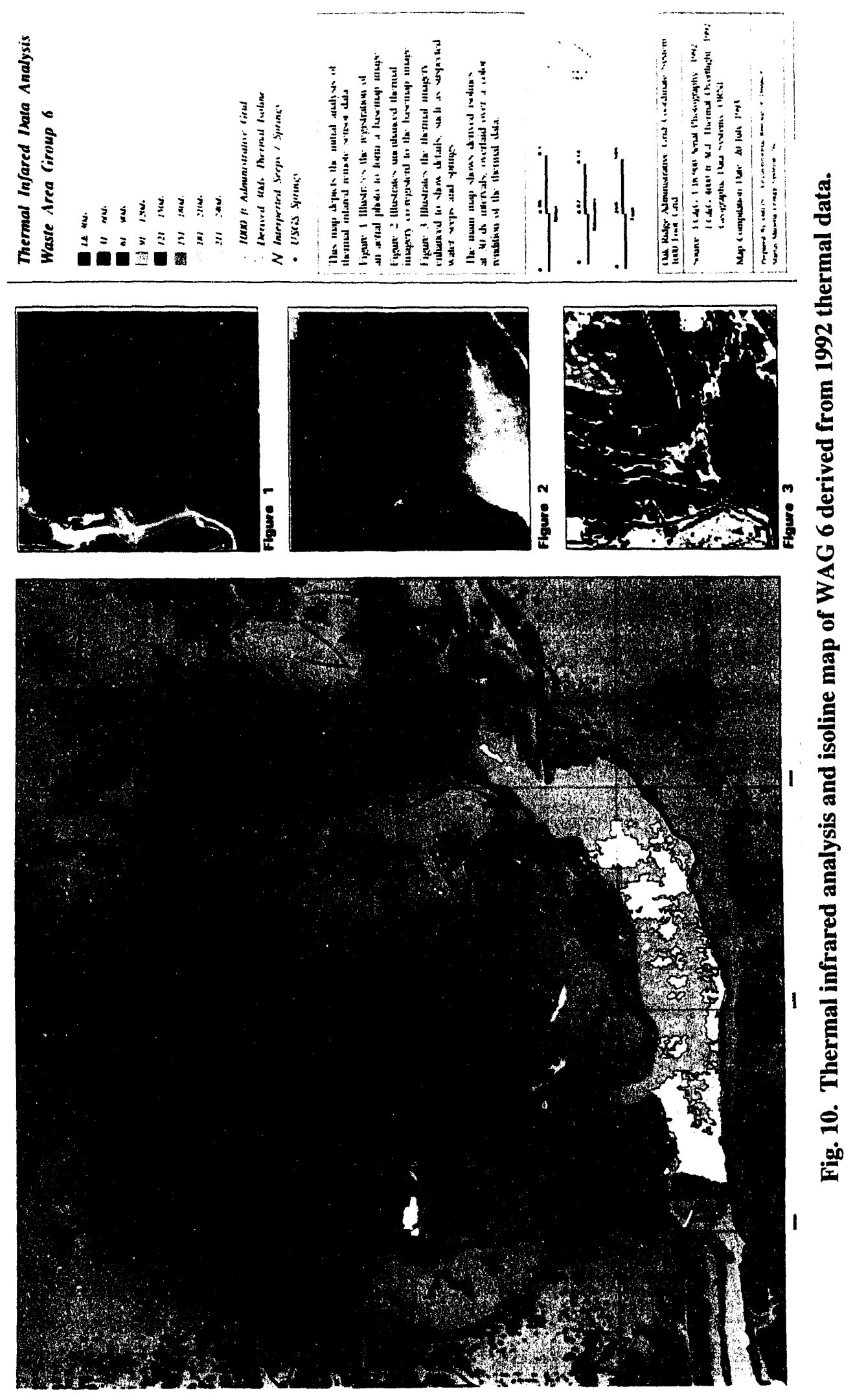


- loading and transforming the data into useful forms for analysis;

- managing the vast volumes of data under configuration control;

- applying the data to ER problems using specific analysis techniques integrating ancillary data;

- producing and documenting the results with appropriate refinements and new data collection as required;

Work has been performed in each of the areas listed using the ORR Phase I data. Further collection efforts are planned for remotely-sensed data similar to that used in Phase I, plus some additional acquisition technologies [e.g., laser-induced fluorescence (LIF)]. Although Oak Ridge is a leader in remote sensing, the process of obtaining and applying these data on the ORR has just begun. A number of developments and applications are underway to support efforts in all five of the listed areas.

Examples of follow-on activities include processing, analyzing, and mapping the recently completed PORTS gamma survey. Acquisition of new MSS imagery and aerial photography will be carried out for portions of the ORR so that change detection and updates of hazardous waste activities can be done. Land use and land cover information will be computed for major portions of the rest of the ORR to aid other surveys such as wetlands, natural resources, forest inventories, and habitat and endangered species studies. Improved digital elevation models will be created and validated using stereo photography for use in all types of hydrologic and terrain studies. Other sources of gamma radiation data (e.g., the Geonex Aerodat, Inc., study and walkover surveys) will be compared and mapped with the existing EG\&G Energy Measurements gamma radiation data to study anomalies and differences. All of the gamma radiation information will be placed under configuration control procedures.

An effort is planned with EG\&G, Las Vegas, to acquire all the historical photographs, MSS imagery, and gamma radiation data for the ORR, PORTS, and PGDP. Another project is underway with TVA to acquire and analyze all the historic imagery that can be found from any federal, state, or private agency that has flown over the ORR from the preconstruction period (1930s) to the present. This information will be computerized to allow analysis of changes over time that may be related to past waste activities. By linking this information with historic documentation, it may be possible to identify previous contaminant sources and their disposition. Changes in topography from preconstruction to current conditions will help identify potential conduits for pollutant migration and the study of surficial geologic characteristics.

Development will continue to implement an image browse and retrieval system including the incorporation of an optical jukebox storage device to handle the thousands of images efficiently. Hardware and software development will provide a high-resolution scanning system, 24-bit photographic color hard copy output, new imaging and visualization capabilities to analyze large volumes of data, further integration of video and digital data within a GIS environment, and computer stereovision for 3-D photogrammetric analysis that will also support a variety of terrain studies and modeling efforts.

Configuration control and data management procedures, as well as formal inventory and cataloguing systems within the geo-data repository, will continue to be established. Metadata 
development, storage, and access will be expanded significantly to document all the raster and vector imagery products being handled and to identify their suitability for different applications. Standardized distribution and updating techniques will be implemented to maximize usefulness of the different types of data.

\subsubsection{Phase II Geophysical Surve s}

\subsubsection{Survey Specifications}

Phase II of the 1992 survey used geophysical techniques to aid in detecting certain types of subsurface anomalies. Phase II was initiated in November 1992 and consisted of simultaneous helicopter electromagnetic (HEM), magnetic, and gamma radiation surveys of the entire ORR, except for the main plant areas. Both manmade (drums, trench boundaries, burn pits, well heads) and geologic (fractures, faults, karst features, geologic contacts) features were the targets for this survey. Phase II was undertaken in three stages: testing, reconnaissance, and high-resolution data acquisition. The testing stage used two integrated $\mathrm{HEM}$ /magnetic gradiometer/very low frequency-EM/radiometric systems. System A (Big Bird) was designed for reconnaissance surveying to be flown at a nominal survey altitude of $30 \mathrm{~m}$ AGL, while the "high-resolution" System B (Little Bird) was designed to permit surveying at altitudes as low as $5 \mathrm{~m} \mathrm{AGL}$ for detailed location and identification of targets. The two systems were tested at five reservation sites chosen for their various known features. The goal of this testing stage of the survey was to determine the accuracy and precision of the two systems in identifying the known features of the test areas and to select the parameters for the reconnaissance survey. The reconnaissance stage used Big Bird to acquire data over the entire ORR using a flight line spacing of $150 \mathrm{ft}(46 \mathrm{~m})$ at an altitude of $100 \mathrm{ft}(30 \mathrm{~m})$. This section of the survey was designed for detection of large environmental targets and for characterizing those geologic features that possibly influence contaminant migration (e.g., faults and fractures) or the features that must be taken into consideration when evaluating higher-resolution data. Once the data from these two sections have been further analyzed, sites will be chosen for the final section of the survey, high-resolution data acquisition.

\subsubsection{Preliminary Results}

Early preliminary map products demonstrated that the magnetic data are most sensitive to buried and exposed metals while the EM data are most sensitive to geological features. Figure 11 is a vertical magnetic gradient map of waste area grouping (WAG) 6 highlighting the waste areas and WAG 6 boundaries and noting the differing levels of sensitivity to silos versus biological trenches. Figure 12 is an apparent conductivity map of the entire ORR derived from EM data collected during the reconnaissance stage of the Phase II surveys with ORR geology contacts overlaid. This demonstrates that simultaneous airborne EM and magnetic data acquisition ideally suited to site characterization where one is concerned with locating waste and determining possible contamination pathways from the waste sites.

Although final products will not be received from the subcontractor until the end of November 1993, preliminary data have already shown advantageous uses for ER site

investigations. In a general sense, the data have indicated that both EM and magnetic methods can delineate the boundaries of waste sites. In the limited portion of the data examined to date, no indications of large, previously unknown waste sites on the ORR have 


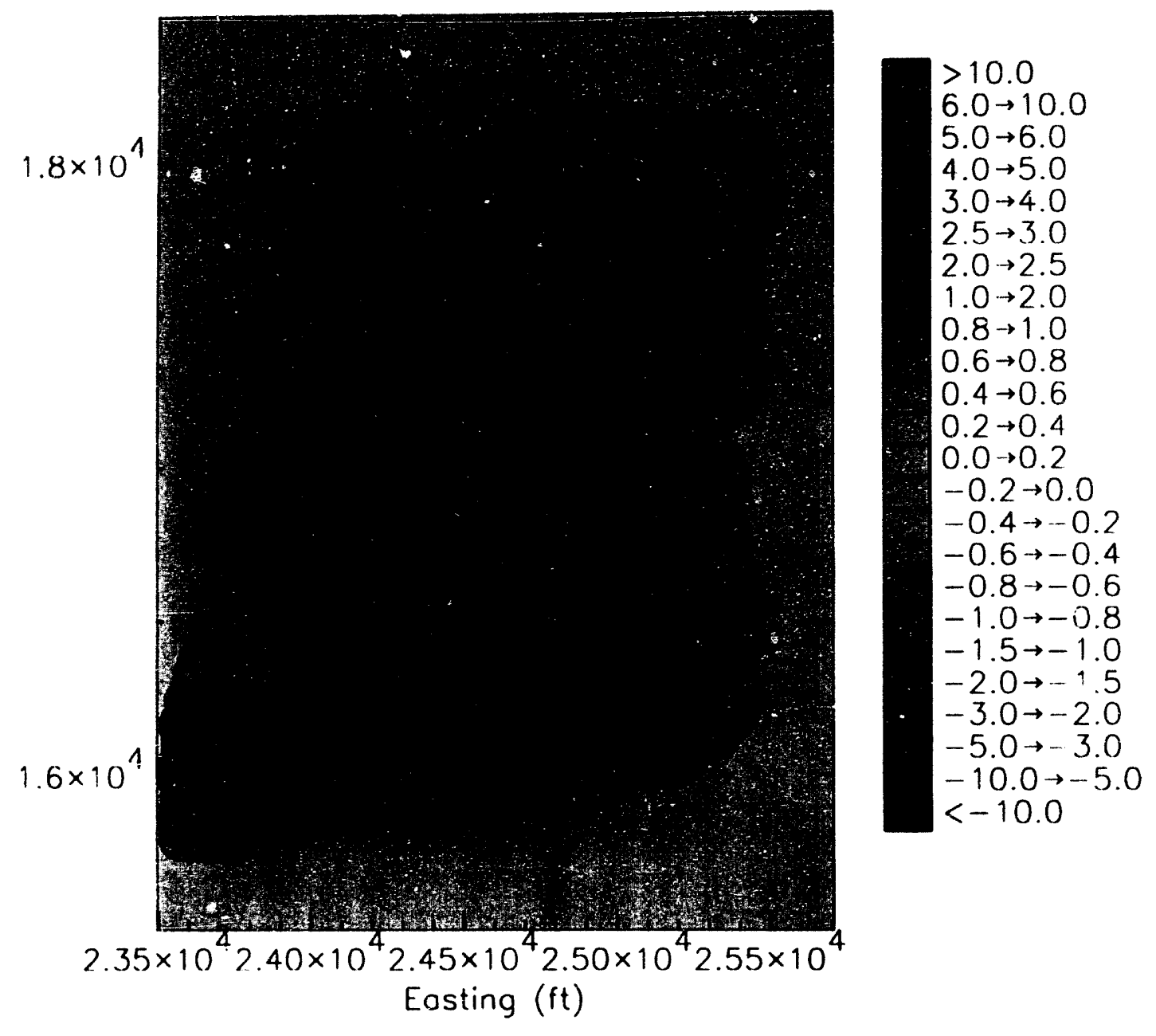

Fig. 11. Vertical magnetic gradient map of the WAG 6 waste site. 


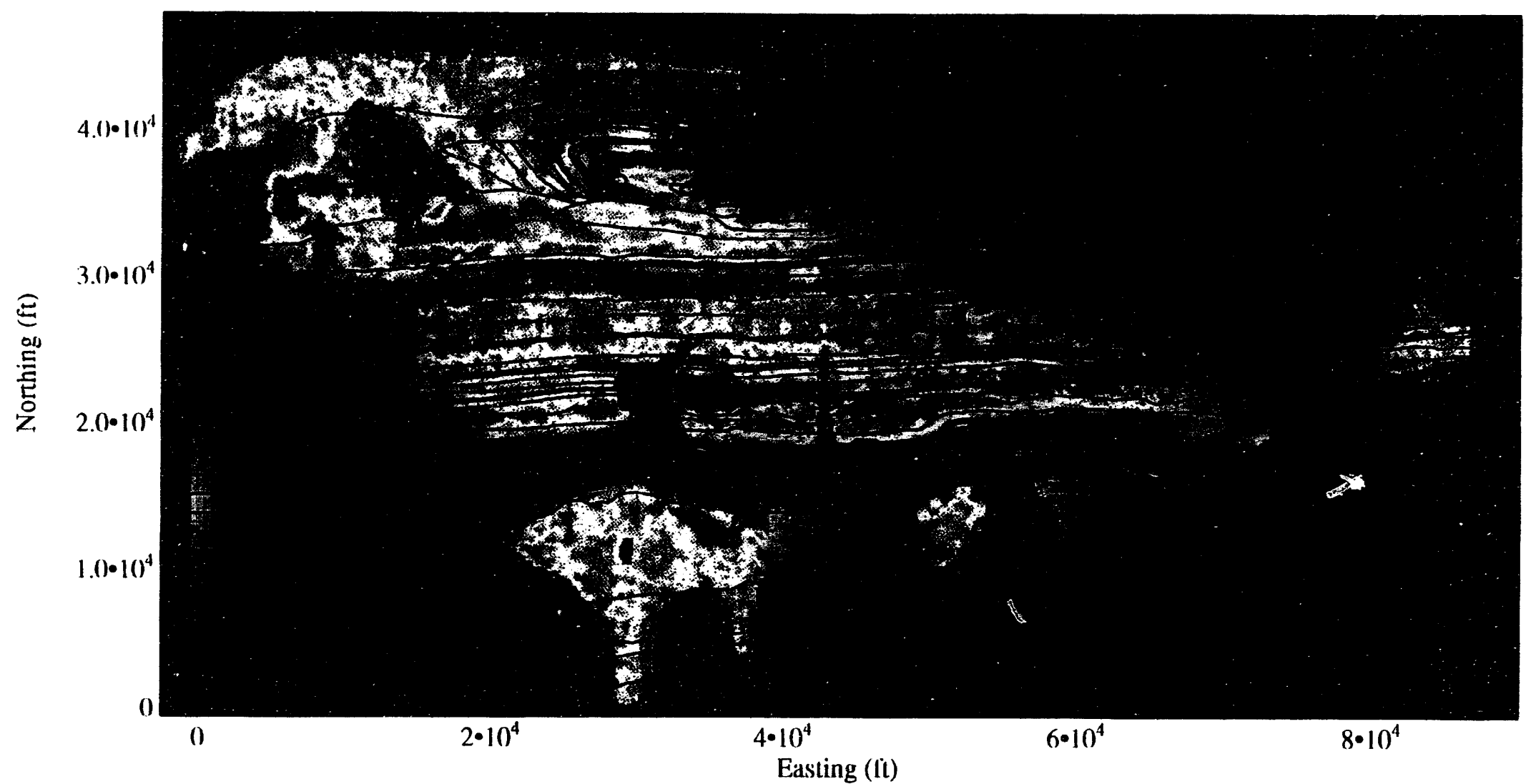

Fig. 12. Apparent electrical conductivity map of the Oak Ridge Reservation derived from Phase II electromagnetic surveys. 
been seen. A list of projects highlighting uses of preliminary airborne geophysical data follows:

- Magnetic and EM maps from the airborne geophysical surveys have been provided to the Freels Bend site ER remedial investigation team. These data will be used to select areas or more localized ground-based site investigations.

- Airborne magnetic data are being used to set the parameters for a surface magnetic survey of White Wing Scrapyard.

- Phase II airborne geophysical data are being used to provide background data for subsequent geophysical investigations to identify karstified limestones and might be used to map the depth to a brine layer which represents the bottom of the ORNL Groundwater Operable Unit (GWOU). These geological investigations are part of the ER investigation of the ORNL GWOU.

- Complex folding and faulting within and adjacent to the K-25 Site may control off-site migration of contaminants. The Phase II airborne geophysical group is working with the geologist responsible for mapping the K-25 geology; the geophysical data are providing confirmation of hypothesized faults and contacts, as well as suggesting areas for subsequent investigations.

\subsubsection{Future Plans}

Application of airborne geophysical methods to environmental sites is in its early developmental stage. To our knowledge, only two similar airborne investigations have been conducted: one for the limited purpose of mapping subsurface brine at Brookhaven, Mississippi, and a second at the DOE's Idaho National Engineering Laboratory (INEL). 'The INEL survey was conducted on a small scale in a less suitable geologic environment and suffered from major acquisition problems. Limited application of helicopter magnetic surveys to environmental targets has occurred in Europe.

Evaluation of the preliminary data from the ORR indicates that sensitivity can be enhanced by developments in all three stages of data handling. The three stages of data handling are acquisition, processing, and interpretation. New or improved acquisition tools and processing methods, and streamlined interpretation procedures will lead to more useful data and more complete site information. For example, the smaller footprint (ground detection area) of EM coils in a vertical coaxial configuration implies that greater sensitivity could be achieved by using that configuration in a high resolution system rather than horizontal coplanar coils; detection of subtle metallic targets could be enhanced by applying Euler filters to the magnetic data; and discrimination between transient magnetic targets (e.g., vehicles) and waste could be handled efficiently by the development of video scanning systems which would allow instantaneous inspection of video images which are acquired during data acquisition over a particular anomaly. These examples highlight the primary difference between airborne mineral exploration and environmental site characterization: mineral exploration systems discriminate against the high frequency and high amplitude signals characteristic of specific targets. Because the data acquired with existing systems have already proven useful, it is believed that further development of acquisition and data handling procedures will lead to significantly improved sensitivity from these systems. The subcontractor, Geonex Aerodat, Inc., is currently working with ER Program personnel to 
improve system designs for the upcoming high resolution survey, and the U.S. Geological Survey is working with project personnel to develop improved data processing tools.

Short-term plans include processing and analyzing data collected in fiscal year (FY) 1993 in anticipation of high-resolution airborne surveillance scheduled for FY 1994. The advantages of different coil configurations are being evaluated, and sites for high-resolution surveillance are being selected. Ground surveys will also be conducted at selected ORR sites to evaluate anomalies and the sensitivity of the airborne data. Long-term plans (6 months to 2 years) include the development of data processing and interpretation schemes that will be used to benefit local ER programs. Improved acquisition systems will be tested if they appear to produce maps with significantly improved resolution that would be cost effective when compared to surface investigations. In later stages of the ER life cycle, airborne geophysical data may be used for site monitoring purposes. To date, no evidence in surface-based measurements has been discovered that suggests the data are detecting significant effects from processes that vary over periods of a few days or months. Unless there is evidence that transient behavior of important subsurface processes can be mapped with geophysical methods, periodic or routine airborne geophysical surveys of the ORR are not anticipated. High-resolution airborne and ground-based surveys of selected sites will be conducted, as needed, if appropriate and cost-effective. Specialized processing will continue in support of ER site characterization and possibly monitoring programs.

\subsection{PADUCAH GASEOUS DIFFUSION PLANT}

The first radiological survey was conducted in 1976 by EG\&G Energy Measurements, Inc., at an altitude of $200 \mathrm{ft}(61 \mathrm{~m}) \mathrm{AGL}$ and flown at 70 knots. A second radiological survey was made on May 15-25, 1990, and was flown under the same conditions as in 1976. The 1990 survey examined 62 square $\mathrm{km}$ that included PGDP, the West Kentucky State Wildlife Management Area, and the area extending north of the facility to the Ohio River. Flight line spacing was $350 \mathrm{ft}(107 \mathrm{~m})$ resulting in a total of $71 \mathrm{flight}$ lines. The only manmade radionuclide detected within the facility in both the 1976 and 1990 surveys was protactinium (protactinium-234). This is indicative of a uranium-238 source. Anomalous areas detected within the PGDP in 1990 were the same as detected in 1976.

A 12-channel, MSS survey was conducted on May 31, 1990, at $3000 \mathrm{ft}$ (914 m) AGL, using $11 \mathrm{flight}$ lines with spacings of $3000 \mathrm{ft}(914 \mathrm{~m})$. A predawn digital thermal IR survey was made on June 1, 1990, at $3000 \mathrm{ft}(914 \mathrm{~m})$ AGL. Color and color IR photographs of the facilities were obtained on March 20,1990, at altitudes varying from 4000 to 25,000 ft AGL $(1219$ to $7620 \mathrm{~m})$. Airborne geophysical surveys are unlikely to be conducted at the PGDP because of the high concentration of buildings and metallic debris at the surface.

\subsection{PORTSMOUTH GASEOUS DIFFUSION PLANT}

Radiological surveys were conducted by EG\&G in 1984 and 1990 of the 83 square $\mathrm{km}$ area of PORTS and its surroundings. During July 11-20,1990, the radiological survey was conducted at a nominal altitude of $300 \mathrm{ft}(91 \mathrm{~m})$ and at a line spacing of $400 \mathrm{ft}(122 \mathrm{~m})$. Protactinium (protactinium-234), a uranium-238 decay product, was shown at five locations within the facilities. Gamma activity indicative of uranium-235 was detected over the gaseous diffusion buildings. No manmade radiation was found outside the plant. 
The most recent radiological survey was conducted during August 1993 and preliminary results show no change in the sources of manmade radionuclides at the facility as identified in previous surveys. Surface measurements are being conducted at PORTS to determine whether airborne geophysical surveys could prove useful.

\section{SPECIAL PROJECTS}

Many special projects have resulted from the ER Remote Sensing and Special Surveys Program activities. Digital Spatial Data Base Projects for the ORR, PGDP, and PORTS, LIF technology tests, and support for Vice President Gore's Environmental Task Force (ETF) are three such special projects.

\subsection{DIGITAL SPATIAL DATA BASE}

An Interagency Agreement (IAG) with TVA is in place for the primary objective of producing digital and hard copy data bases suitable for all types of environmental assessments, remediation studies, engineering planning, data validation, and monitoring activities for the ORR, PGDP, and PORTS. The task will also demonstrate the use of aerial photography collected from aircraft with a real-time airborne ground positioning system that significantly improves rectification of the data bases.

Three main types of data will be generated from the task. The ORR will be divided into more than 200 areas $(1750 \times 1750 \mathrm{~m}$ tiles $)$ and digital ortho-normal rectified natural color mosaics of these areas will be prepared in the NAD83 State Plane coordinate system. Digital elevation models will be generated for the ground surface topography, including 5-ft contours or the ORR. Surface features will be computerized with a horizontal accuracy on a scale of $1=200 \mathrm{ft}(60.96 \mathrm{~m})$. Planimetric, hydrologic, topographic, land use, land cover, and other thematic features will be stored in a vector-based topologic structure suitable for use in the OREIS. Annotations and the coordinate system data will also be linked with the attribute data for the thematic features. This kind of fusion of remotely-sensed, thematic, and environmental data is illustrated in Fig. 13.

The products from this activity include hard copy photos and mylars in natural color, black and white, and color IR for each of the map tiles and for the ORR at other selected scales. Hard copy maps of the ORR will be generated at a number of selected scales. A replacement for the current S-16A map of the reservation will be generated with a resolution that will be 10 times greater than the prior mapping in 1986-87. Image data bases will be provided on CD-ROM media suitable for direct use in geographical information systems. Full documentation will be provided for all products. Similar projects are currently being planned for PORTS and PGDP. 


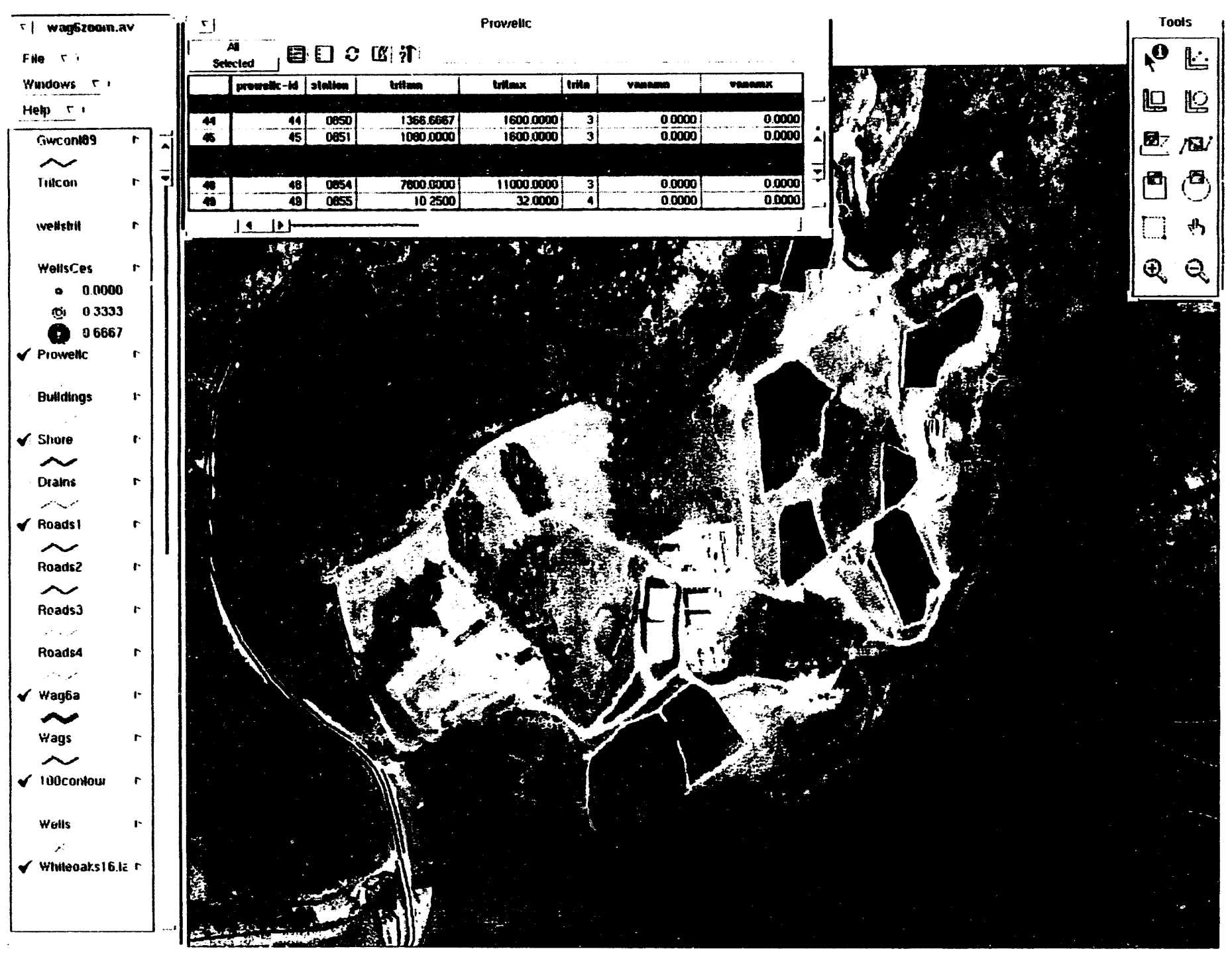

Fig. 13. A sample Geographic Information System screen showing monitoring wells in WAG 6 mapped on top of rectified aerial photography and map data along with an interactive table of pollutant concentrations. 


\subsection{LASER-INDUCED FLUORESCENCE}

During June 1993, scientists from EG\&G Energy Measurements, Inc., Santa Barbara Operations visited the ORR to test a new LIF technology. Measurements were made to detect surface uranium contamination and to evaluate the influence of vegetation stress on fluorescence of foliage. Fluorescence associated with uranium oxides were recorded using gated video cameras and gated array detector/spectrometers from measurements taken at Building K-27 of the K-25 Site complex. Prompt and persistent fluorescence was recorded on video cameras, and spectra of the various signatures were recorded. The oxides are believed to be primarily $\mathrm{UO}_{2} \mathrm{~F}_{2}$ as thin films in the facility. Uranium emissions were recorded as persistent phosphorescence (fluorescence) and these were confirmed with alpha meters. Other materials such as asbestos, calcium silicate, and oils were evident in the prompt emissions recorded as video.

The LIF measurements were made of sweet gum (Liquidambar styraciflua) trees at the Global Change facility on Walker Branch watershed before and after three days of ozone exposure at approximately $150 \mathrm{ppb}$. No visible symptoms of stress were evident, however physiological measurements of foliar respiration were made and these results will be compared with the LIF analysis. Additional LIF measurements were made in a loblolly pine (Pinus taeda) plantation on healthy and pine beetle infested trees. Further data analysis will determine spectral comparisons of any stress indicators.

\subsection{ENVIRONMENTAL TASK FORCE}

During July 1993, the Remote Sensing and Special Surveys program sent a proposal to Vice President Al Gore's ETF for conducting analysis of national technical means (NTM) technology at the ORR. The proposal contained general information about the ORR facilities and the ER Program. The proposal also contained detailed information about several sites located on the ORR that are of interest to the ETF for determining the relevance of using classified imagery for environmental restoration purposes. The integration of high resolution remotely sensed NTM data with existing geographic and environmental data could prove to be useful in all stages of the hazardous waste site remediation life cycle.

As a result of the ETF proposal, an applied research study has been initiated for the Strategic Environmental Research and Development Project (SERDP). An execution plan and a ground truth collection plan have been developed to implement the investigation of applying NTM classified imagery to waste site characterization, monitoring, and remediation. The initial study will be conducted from October 1993 to March 1994. During this time, satellite imagery data will be collected from NTM technology, and ground-based data will be collected in accordance with the ground truth collection plan. These data sets will be gathered periodically and simultaneously. Once these data sets have been collected, they will be closely compared and an initial evaluation will be made. 


\section{DATA MANAGEMENT}

\subsection{OAK RIDGE ENVIRONMENTAL INFORMATION SYSTEM}

An important advance in data management has been established as part of the environmental restoration and waste management programs administered by the DOE Oak Ridge Operations (ORO) Office. A comprehensive compilation of environmental, hydrologic, and chemical monitoring data from the ORR are being assembled as part of environmental restoration activities for the Y-12 Plant and K-25 Site facilities, ORNL, and off-site areas. The information system, known as OREIS, will also include environmental data from the DOE facilities at PGDP and PORTS.

The OREIS provides the ability to input, analyze, and display environmental and geographic information through the integration of three primary software packages: a database management system (ORACLE), a statistical analysis and display system (SAS), and a geographic information system (ARC/INFO). User friendly interfaces are being developed to facilitate ready access to the data and software tools. The OREIS effort also includes extensive data management procedures, configuration control of the data, and strict quality assurance and quality control (QA/QC) protocols for the data entered into OREIS. An example of data fusion that can be made with the system is the overlay of groundwater contours and selected groundwater quality data (based on user-specified queries) with various maps (facilities, operable units, topography) or with georectified imagery obtained from remote sensing. This system will also serve to meet the data repository, management, and access needs under the Federal Facility Agreement (FFA) and state oversight agreements [e.g., Tennessee Oversight Agreement (TOA)].

\subsection{DATA PROCESSING AND IMAGE ANALYSIS}

The extensive information received from remote sensing and aerial survey instruments is carefully incorporated into formats that will optimize the utility of the information for use in environmental surveillance, restoration, and public relations. Data are input, rectified, analyzed, and stored along with supporting information, according to the series of flowchart steps shown in Fig. 14. A number of products can be derived from the stored images (examples are given in Sect. 7.3) making the digital records a flexible and comprehensive resource for many uses.

The configuration control applied to data bases from ground observations will be applied to the aerial survey data as they are collected, received, catalogued, validated, stored, and maintained. The work begins with mission planning, coordination, and preparation of flight line maps. The digital data must undergo geometric and radiometric processing to extract features and interpretations useful in OREIS. Digital results are incorporated into the OREIS system to supplement other environmental and hydro-geochemical monitoring data for use by researchers, planners, engineers, and management. These results also help support the FFA and the TOA. Because of the large amount of imagery and data, browse capabilities and index maps are needed to provide quick reviews of available data across the ORR and off-site areas. Hard copy products and data extracts must be created for distribution to a wide range of investigators. 


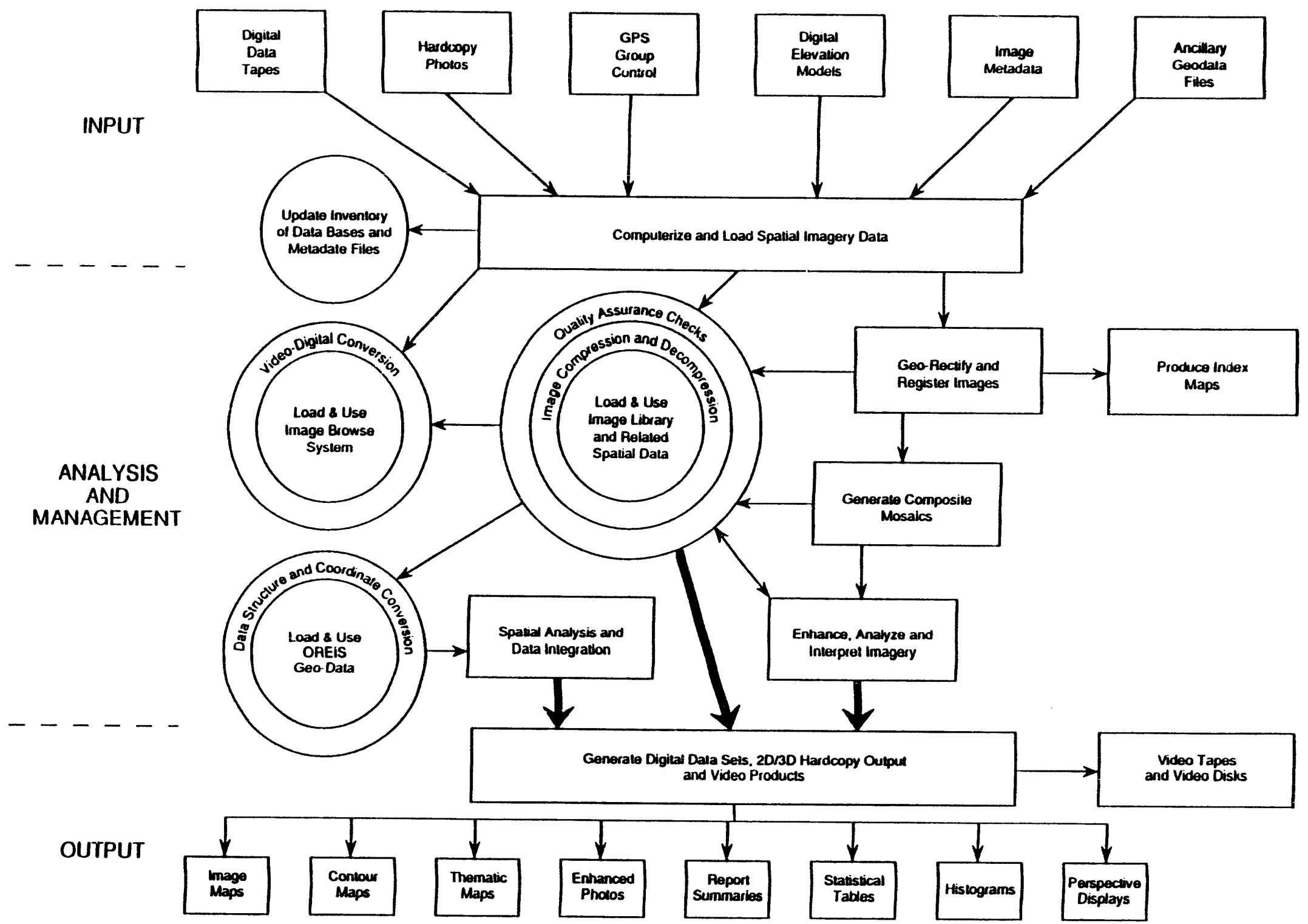

Fig. 14. Flowchart showing how geographic and remotely sensed data are input, rectified, analyzed, and stored. 
A considerable amount of data preparation and image processing is required to integrate these results within the OREIS systems and data bases. The processing includes high resolution scanning of natural color and color IR photographs for conversion to digital formats, pre-processing of the MSS data to create manageable image files, establishment of ground control points for rectification of images to standard coordinate systems such as State Plane 1983, 3-D terrain modeling from sterco imagery, creating orthophotos to correct for $x-y$ positional terrain distortions in lower altitude ( 3000 and $6000 \mathrm{ft} A G L)$ photography, and mosaicking of rectified images. Common coordinate systems and file formats must be created to allow combination and overlay of S-16A and other thematic data such as the reservation and operable unit boundaries, elevation contours, and gamma contours. Rectified thermal contour data must be computed from predawn MSS thermal bands (channels 11 and 12) for image overlays and interpretation. Image indexing procedures, data storage, and data retrieval strategies will be established to handle large volumes of image data.

The radiometrically calibrated, 12-band, MSS data from $6000 \mathrm{ft}$ (1829 m) AGL alone requires $\mathbf{5 0 0}$ megabytes of storage. To overlay and combine other information, the MSS data must be geographically rectified. Land use/vegetative classification and interpretation requires extended analysis outside OREIS by specialized remote sensing software and hardware before it can be incorporated with other OREIS data. The scanned and processed aerial photography and MSS data from different altitudes require many gigabytes of data storage.

\subsection{DATA AND HARD COPY PRODUCTS}

A number of digital and hard copy products can be derived from remote sensing and aerial survey instrumentation, both in raw form and as a consequence of the data and image analysis steps described in the preceding section. These products can be useful for detailed analysis and interpretation of past and present environmental conditions relating to hazardous waste activities on the ORR. When integrated with other types of existing geographic and environmental data, they are invaluable in computer-assisted environmental analysis and site characterization. Example products anticipated from the remote sensing program follow.

\section{Aerial Photography Products}

ortho-mosaic images as reference underlays (e.g., Fig. 7);

- false color IR image maps (e.g., Fig. 5);

- digital oblique photographs;

- enhanced color photograph data sets in multiple grid systems;

- image maps overlaid with vector-based map features (e.g., Fig. 13).

\section{MSS-Derived Products}

- land use/land cover maps (e.g., Fig. 8);

- enhanced vegetation indices maps (e.g., Fig. 9);

- enhanced band-ratio maps;

- change-detection images with class statistics; 
- atlas of pseudo-colored MSS image strips;

- enhanced imagery of all types.

Thermal Imagery Analysis

- thermal contour maps (e.g., Fig. 10);

- image maps of candidate seep areas;

- color composites of thermal imagery and aerial photographs.

\section{Gamma Radiation Survey Results}

- radiological contour maps (e.g., Fig. 6);

- gamma contours overlain on aerial photographs (e.g., Fig. 7);

- radionuclide contours superimposed on 3-D landform.

\section{Terrain Products}

- three dimensional perspective displays of images on elevation surfaces (e.g., Fig. 7);

- digital elevation models;

- topographic contour maps and data sets;

- slope, aspect, and visibility maps;

- animated terrain surface sequences;

- profiles and cross sections.

\section{Reference Maps and Planimetric Data}

- flightline maps;

- aerial coverage maps by imagery type;

- planimetric maps and data bases;

- updated facility data;

- ground control points and benchmarks.

Video-Captured Data

- video tapes and video disks;

- digital images captured from video frames;

- sequences of subsampled video frames. 


\section{Tabular Reports}

- statistical summaries and frequency distributions;

- perimeter and area computations.

\section{THE SAVANNAH RIVER SITE EXPERIENCE}

Aerial surveillance at the DOE Savannah River Site (SRS) has been an on-going activity since the late $1950 \mathrm{~s}$. The SRS consists of approximately 500 square miles (1295 square $\mathrm{km}$ ) of federally-owned land and is more than 10 times the area of the ORR. The SRS is located in Aiken and Barnwell counties, South Carolina. The SRS aerial surveillance program uses gamma radiation detection, MSS imagery, and oblique photography and videography to document SRS activities.

The SRS Aerial Surveillance Program Manager is willing to work with DOE-ORO and Energy Systems in reducing aerial survey costs by sharing set-up costs whenever possible.

\section{NEW DEVELOPMENTS IN REMOTE SENSING TECHINIQUES}

Several new developments in remote sensing techniques offer potentially enhanced sensitivity in detection of waste sites, contamination impacts (e.g., stress vegetation), and groundwater seeps. Some new surveillance methods include:

- multiband and narrow-band photography;

- shortwave infrared video;

- hyperspectral monitoring;

- shortwave thermal (3-5 m) imaging;

- ground-penetrating radar;

- luminescence (laser fluorescence);

- airborne gas detection; and

- improved digital EM systems.

Some of these techniques are experimental and interpretation of results could be enhanced with the application of several techniques at the same location. 


\section{PLAN FOR SURVEILLANCE, MONITORING, DATA MANAGEMENT AND ANAZYYSIS}

While specific recommendations are made in this report for routine monitoring of the DOE-ORO facilities, a proposed strategy for the development of surveillance requirements for the optimum collection of data to support the DOE-ORO ER Program is as follows. A phased approach for the collection of the appropriate characterization and/or monitoring data is required. The first step in this approach is to study current characterization and/or monitoring data (on ha'd) to determine what data are necessary for the trending of specific problems. The second step of this approach is to study historical remote sensing imagery, aerial photography, and conventional characterization/monitoring data to determine specific areas of the DOE-ORO facilities to be studied (e.g., waste site areas, areas that display characteristics of previously unknown waste sites). Based on the first two steps of the approach, a collection plan to capture the required data must be established. Upon receipt of the collected data sets from the subcontractor, the program will apply data management routines and appropriate data analyses to best utilize the collected data. The final step if this phased approach is to assess the surveillance requirements, data collection, and data analysis and management routines that have been conducted to ensure the program is efficiently collecting appropriate, usable data to support the DOE-ORO ER Program in ways that are not possible by conventional site characterization and/or monitoring methods or are most cost-effectively collected by remote means. These steps will be carried out by the ER Remote Sensing and Special Surveys Program in coordination with personnel of the ER Site Programs.

\subsection{MULTISPECTRAL IMAGERY AND AERIAL PHOTOGRAPHY}

The MSS imagery, false color IR photography, and natural color photography are recommended for routine monitoring of the ORR, PGDP, and PORTS facilities and their associated off-site areas in surveys that would be conducted once per year with flights alternating between late winter and middle to late summer on 2-year cycles. Late winter (February-March) is an excellent time to identify groundwater seeps and thermal effluent release sites because the deciduous vegetation is without foliage and seeps are active. This is also an optimum time to update facility, planimetric, and topographic data bases since ground visibility is at a maximum. Vegetation stress is most easily identified in mid-summer (August) after spring growth has been completed and vegetation is in full leaf and when soil water content is at a low level for the year. Summer is also a suitable time for land use characterization.

\subsection{RADIOLOGICAL SURVEYS}

Gamma radiation surveys are recommended for routine monitoring at 3-year intervals. Where possible, aerial surveillance flights will be coordinated with similar activities at SRS in South Carolina using EG\&G Energy Measurements, Inc., staff and equipment. This is expected to give an efficient sharing of resources and reduce set-up time costs. Radiological surveys of land and shoreline areas are best conducted when soils are dry and at times when stream water levels are low so that an extensive area of shoreline is exposed. Special 
radiological surveys may be conducted as needed for unusual situations that may arise during the 3-year survey interval.

\section{PERSONNEL}

The operations of the Strategic Plan will be administered by a Core Team in consultation with a Steering Committee.

\subsection{CORE TEAM}

This committee consists of the following personnel: David Carden (DOE-ORO), Administration and Oversight; David Bell (Energy Systems), Oversight; Amy King (Energy Systems), Program Management; Bill Doll (Energy Systems), Geophysical Specialist; and Richard Durfee (Energy Systems), Spatial Data Specialist.

The duties of the Core Team include (1) planning and implementing remote sensing surveys of the ORR, PGDP, and PORTS, (2) conducting necessary data analysis efforts to provide meaningful data to ER user groups, and (3) providing appropriate survey results to the ER user groups.

\subsection{STEERING COMMITTEE}

The Steering Committee will have representatives from the various users of the remote sensing survey results. The following programs will have up to two representatives on the committee, and the chairperson will be David Bell:

- Environmental Restoration Site Programs

- K-25 ER Program

- ORNL ER Program

- Y-12 ER Program

- Off-site ER Program

- Paducah ER Program

- Portsmouth ER Program

- Oak Ridge Environmental Information System

- Oak Ridge Research Park

- Community Relations

This committee will provide guidance to the Core Team on the scope of remote sensing survey activities and will promote the effective use of survey results in their respective programs. General responsibilities of the Remote Sensing and Special Surveys Program 
Steering Committee include general guidance and oversight of remote sensing survey activities, review of strategic plans, review of progress and results from on-going survey projects, assistance in obtaining funding, and identification of potential survey sites that can benefit froin remote sensing technologies. The Steering Committee will generally meet with Core Team members.

\section{BENEFIT}

Remote sensing surveillance is the most cost-effective and time-efficient means for monitoring large areas of landscape for hazardous waste sites and waste site impacts, particularly in light of the DOE mandated life cycle for cleanup operations. High resolution photographic, multispectral, and radiological data, as well as geophysical data, can be gathered for the ORR, PGDP, and ?ORTS in a timely, cost-effective manner that would be impossible by spot ground surveys. These will be used to improve the resolution of known waste sites and to detect any waste sites that might be previously unknown. They will also be used to monitor remediation efforts and subsurface contaminant transport as the DOE life cycle for cleanup progresses to completion.

Staff throughout Energy Systems and many subcontractors are acquiring and using computer systems to create, process, and analyze environmental data as part of their daily activities. Requests for maps, data, imagery, and results of analyses on remotely sensed data for all areas of the ORR are received almost daily from users. An integrated remote sensing program serves as a focal point for technology, data, and analysis; saves time and money for all concerned; avoids costly mistakes in using insufficient data; avoids duplication of effort; improves compliance with regulatory requirements; avoids delays of all types; significantly improves QAVQC involving spatial data; and provides a data resource needed by all activities on the ORR, PORTS, and PGDP. In itself, coverage on a continual basis is extremely valuable and is a significant aid from an administrative, regulatory, and analytic standpoint (e.g., determining and documenting current operable unit areas, producing valid facility and thematic maps for regulators, assessing impacts and pollutant pathways to determine possible remediation alternatives).

The use of these advanced technologies is critical to conducting a successful ER Program for these DOE facilities. Estimates of the costs for remediating hazardous waste sites is in the multimillions of dollars. Developing and applying these information based technologies can reduce restoration costs by improving efficiency in all phases of the effort and can direct attention to the most serious problems. Considering the savings for cleanup of just a few of the more complex areas, the return on investment can be significant. The ability to collect, manage, and analyze these vast amounts of information is vital to identifying and characterizing the problems, modeling and assessing their impacts, prioritizing and designing effective cleanup solutions, meeting regulatory requirements, and long-term monitoring to verify compliance. 


\section{DISTRIBUTION}

1. D. T. Bell

2. V. J. Brumback

3. S. R. Conder

4. K. W. Cook

5. R. B. Cook

6. D. G. Cope

7. M. F. P. DeLozier

8. D. M. Matteo

9-12. W. E. Doll

13-17. R. C. Durfee

18. P. L. Goddard

19. J. T. Grumski

20. P. J. Halsey

21. K. G. Kahl

22. B. L. Kimmel

23-32. A. D. King

33. D. A. Levine

34. R. J. Luxmoore

35-36. D. M. Matteo

37. D. B. Miller

38-43. J. E. Nyquist

44-45. P. T. Owen

46. C. Rightmire

47. G. E. Rymer

48. T. D. Taylor

49. C. C. Travis

50. R. K. White

51. J. S. Cooley

52. Central Research Library

53-55. ER Document Management Center

56. ORNL Laboratory Records

57. D. J. Barnes, EM-423, Trevion 2/HQ, 19901 Germantown Rd., Germantown, MD 20874-1290

58-68. D. M. Carden, DOE Oak Ridge Operations Office, P.O. Box 2001, Oak Ridge, TN 37831-8541

69. C. S. Gist, DOE Oak Ridge Operations Office, P.O. Box 2001, Oak Ridge, TN 37831-8541

70. W. N. Lingle, DOE Oak Ridge Operations Office, P.O. Box 2001, Oak Ridge, TN 37831-8541

71. S. P. Riddle, DOE Oak Ridge Operations Office, P.O. Box 2001, Oak Ridge, TN 37831-8541

72. R. C. Sleeman, DOE Oak Ridge Operations Office, P.O. Box 2001, Oak Ridge, TN 37831-8541 
11
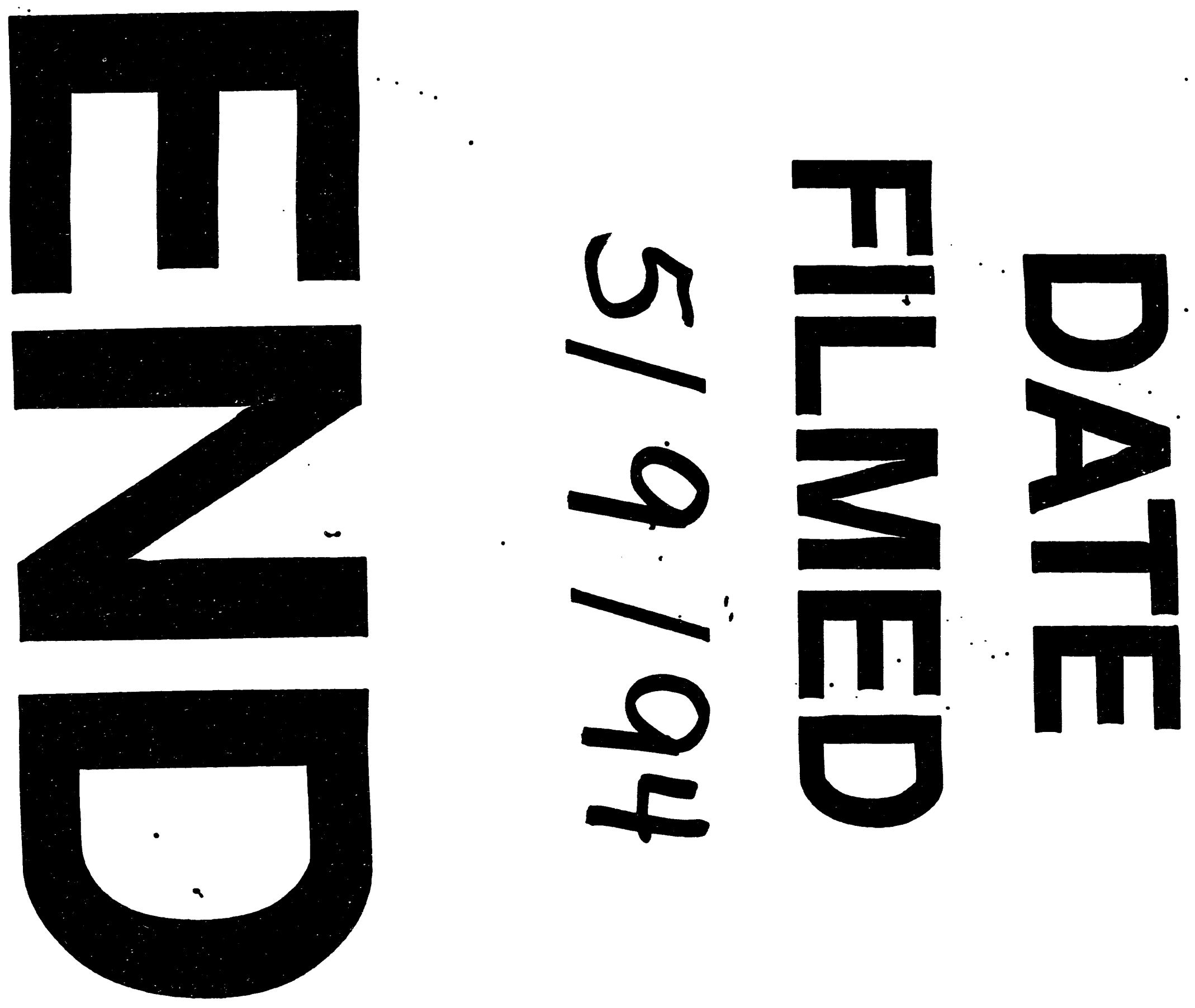
